\title{
Alginate Particles as Platform for Drug Delivery by the Oral Route: State-of-the-Art
}

\author{
Alejandro Sosnik \\ Group of Pharmaceutical Nanomaterials Science, Department of Materials Science and Engineering, \\ Technion-Israel Institute of Technology De-Jur Building, Office 607, Technion City, 32000 Haifa, Israel \\ Correspondence should be addressed to Alejandro Sosnik; alesosnik@gmail.com
}

Received 12 January 2014; Accepted 25 February 2014; Published 9 April 2014

Academic Editors: Y. Ding, Y. Murata, S. Raic-Malic, and V. B. Sunderland

Copyright (C) 2014 Alejandro Sosnik. This is an open access article distributed under the Creative Commons Attribution License, which permits unrestricted use, distribution, and reproduction in any medium, provided the original work is properly cited.

\begin{abstract}
Pharmaceutical research and development aims to design products with ensured safety, quality, and efficacy to treat disease. To make the process more rational, coherent, efficient, and cost-effective, the field of Pharmaceutical Materials Science has emerged as the systematic study of the physicochemical properties and behavior of materials of pharmaceutical interest in relation to product performance. The oral route is the most patient preferred for drug administration. The presence of a mucus layer that covers the entire gastrointestinal tract has been exploited to expand the use of the oral route by developing a mucoadhesive drug delivery system that showed a prolonged residence time. Alginic acid and sodium and potassium alginates have emerged as one of the most extensively explored mucoadhesive biomaterials owing to very good cytocompatibility and biocompatibility, biodegradation, solgel transition properties, and chemical versatility that make possible further modifications to tailor their properties. The present review overviews the most relevant applications of alginate microparticles and nanoparticles for drug administration by the oral route and discusses the perspectives of this biomaterial in the future.
\end{abstract}

\section{Introduction}

Pharmaceutical research and development aims to design products with ensured safety, quality, and efficacy to treat disease. To make the process more rational, coherent, efficient, and cost-effective, the field of Pharmaceutical Materials Science (PMS) has emerged as the systematic study of the physicochemical properties and behavior of materials of pharmaceutical interest (MPIs) in relation to product performance [1]. MPIs are classified into two major groups, active pharmaceutical ingredients (drugs) and nonpharmacologically active pharmaceutical excipients. To systematize this study, PMS adopted the fundamentals of the materials science tetrahedron (MST): a deep understanding of the structure-properties relationship and the study of processing methods to achieve the expected (bio)pharmaceutic performance in vitro (e.g., mechanical strength, compressibility, physicochemical stability) and in vivo (e.g., bioavailability) $[2,3]$. The most common (bio)pharmaceutic drawback that pharmaceutical scientists face is poor aqueous solubility [4-7], followed by limited drug permeability $[4,7]$ and physicochemical instability [8]. All of them, in one way or another, challenge early stages of drug screening and formulation and decrease oral bioavailability. Adverse effect due to systemic exposure represents another main limitation of the pharmacotherapy [9]. For instance, it is estimated that toxicity is responsible for the attrition of one third of the new drug candidates. In this framework, different microand nanotechnologies have been implemented to enhance the different (bio)pharmaceutic aspects of drugs and to increase the chances of translation into clinics $[10,11]$.

Oral administration (p.o.) is the most extensively used $[12,13]$. Regretfully, p.o. entails a variety of hurdles such as incomplete absorption, degradation in the gastrointestinal tract, hepatic metabolism, and limited bioavailability. In addition, since the gastrointestinal residence time of conventional formulations is relatively short (a few hours), this route is less optimal for sustained release purposes [14].

Mucus is a complex combination of glycoproteins [15] that covers the different segments of the gastrointestinal tract with varying thicknesses and compositions [16] thus 


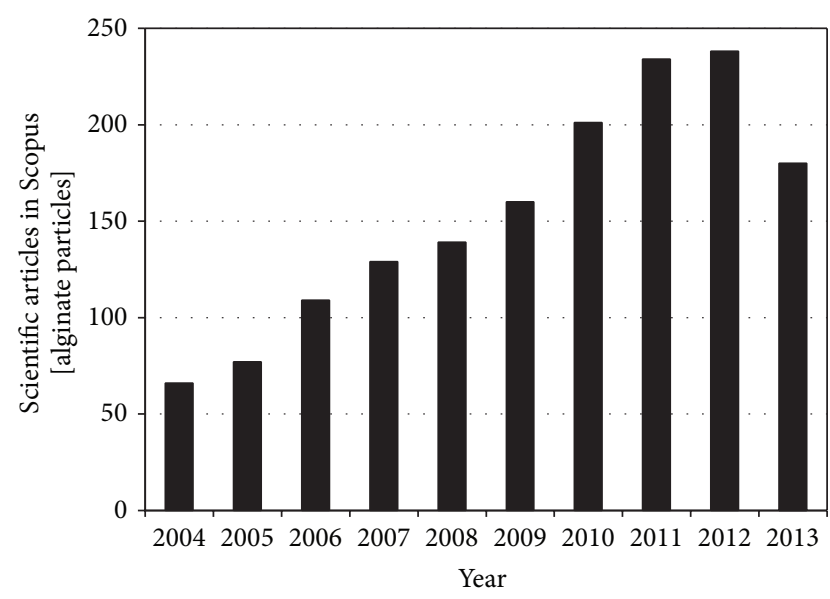

Figure 1: Progression of the number of scientific articles in the search engine Scopus for alginate particles over the last decade.

conferring the mucus well defined rheology, film formation capacity and adhesiveness [15]. These anatomical features have been exploited to expand the use of the oral route. In this context, a broad spectrum of pharmaceutical products that incorporate natural, synthetic, and semisynthetic mucoadhesive excipients have been developed. These excipients, apart from being pharmacologically inert, are expected to establish an intimate interaction with the gastrointestinal mucus and to govern the performance of the drug delivery system upon administration. Since the emergence of microtechnology and nanotechnology, breakthrough progresses have been made in the development of innovative mucoadhesive products for immunization, diagnosis, and treatment of disease [17-20].

Alginic acid and sodium and potassium alginates (ALG) have emerged as one of the most extensively explored mucoadhesive biomaterials owing to very good cytocompatibility and biocompatibility, biodegradation [21], sol-gel transition properties, and chemical versatility that make possible further modifications to tailor its properties [22]. The interest of the scientific community in ALG as a platform for the development of micro and nanodrug delivery systems has given place to a steady growth of the available literature over the last decade (Figure 1). This also found an expression in a rich and growing intellectual property [23]. The present spotlight paper reviews the most relevant applications of ALG microparticles and nanoparticles for drug administration by the oral route.

\section{Structure and Properties of ALG}

ALG is a generic name assigned to a series of natural unbranched polyanionic polysaccharides of $\beta$-D-mannuronic acid (M) and $\alpha$-L-guluronic acid (G) repeating units linked by a $1 \rightarrow 4$ linkage and displaying chain homosequences of MMMMM and GGGGG, interdispersed with MGMGMG heterosequences (Figure 2) [21]. ALG is isolated from a variety of mainly brown algae such as Macrocystis pyrifera, Laminaria hyperborea, and Ascophyllum nodosum [24-26]. Molecular weights in the 32 to $400 \mathrm{~kg} / \mathrm{mol}$ range together with different relative G/M compositions and chain arrangements based on the source of extraction and the age of the algae $[24,27,28]$ resulted in the commercialization of over 200 ALG types [29]. In addition, the rheological and drug delivery performance of ALG is also conditioned by the G/M ratio, the molecular weight, the concentration, and the $\mathrm{pH}$ of the medium. One of the most appealing features of ALG is the ability to crosslink water solutions ionotropically by a mechanism whereby pendant carboxylic acid moieties of $\mathrm{G}$ units chelate $\mathrm{Ca}^{2+}$ and other divalent cations (e.g., $\mathrm{Sr}^{2+}, \mathrm{Ba}^{2+}$ ) to generate $3 \mathrm{D}$ networks $[29,30]$. This gelation mechanism is explained by the "egg-box" model where one divalent cation interacts with four -COOH groups (Figure 3) [31] and it has been exploited over more than three decades for the encapsulation of a broad spectrum of drugs [30, 32], proteins $[33,34]$, genes $[35,36]$, and cells $[21,37-40]$. Another cation that was used to crosslink ALG is Fe(III) [41].

The mechanical and the physical stability of ALG gels depends on the $G$ content, the greater the G content, the more rigid and brittle the matrix. The process can also be reverted in the presence of ion sequestrants such as ethylenediaminetetraacetic acid (EDTA) [42] or sodium citrate [43]. Also, ALG gels tend to be eroded under more neutral and basic $\mathrm{pH}$ values than under acid conditions [44]. This property has motivated its use in the chemical stabilization of drugs and biologicals of oral administration that are not stable in gastric fluids.

From a regulatory point of view, the U.S. Food and Drug Administration (US-FDA) recognizes ALG as a "Generally Referred As Safe" (GRAS) material, a designation that applies to substances accepted as safe for alimentary use by qualified experts [45]. GRAS excipients are listed in the Code of Federal Regulations Title 21 (21 CFR) parts 182 and 184 [46]. This status is very advantageous at the time of the development of products with good chances of bench-to-bedside translation. In addition, ALG is bioadhesive and mucoadhesive, biocompatible and nonirritant, thus finding application in the production of adhesive tablets for buccal drug delivery [47] and wound dressings with different features such as exudates absorption, moisture conservation, and wound healing [48-51]. The prothrombotic activity of ALG has also resulted in its use as haemostat $[52,53]$. At the same time, there is still some controversy regarding specific adverse effects such as immunogenicity $[54,55]$ that would most likely stem from the quality and the level of purity of the biomaterial employed in the different studies [21] and from an intrinsic immunogenic nature, for example, traces of heavy metals, endotoxins, proteins, and polyphenolic compounds that could remain in the final product and lead to undesired effects. When purified in a multistep extraction methodology, no foreign body response was apparent in animals upon intramuscular implantation [38, 56]. These findings supported the hypothesis that adverse effects would stem from impurities rather than from the intrinsic immunogenicity of the biomaterial. Moreover, owing to its gelation capacity, ALG has been exploited in cell encapsulation and immunoisolation $[39,40,57,58]$, endovascular embolization [59], and depot drug delivery [60]. Studies of this kind are 


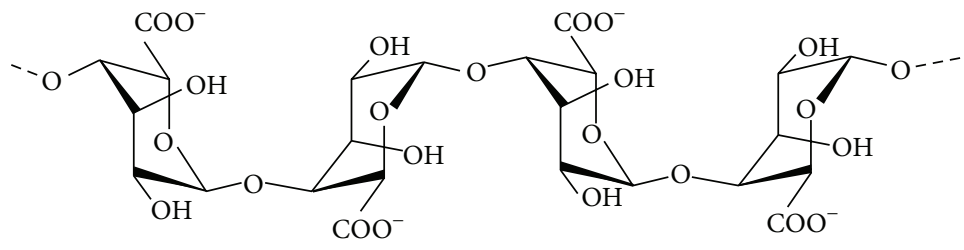

G

G

G

G
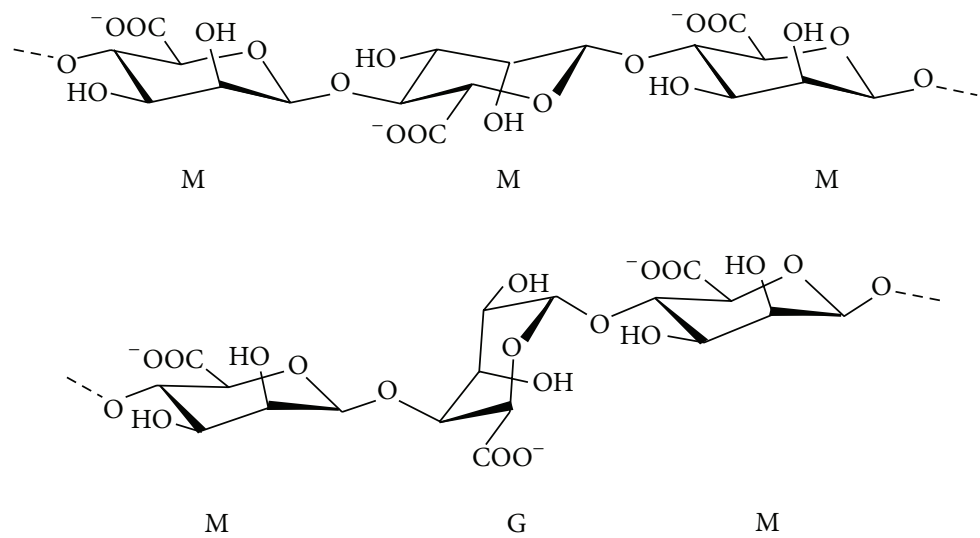

FIGURE 2: Structure of ALG. Reproduced from [21] with permission of Elsevier.
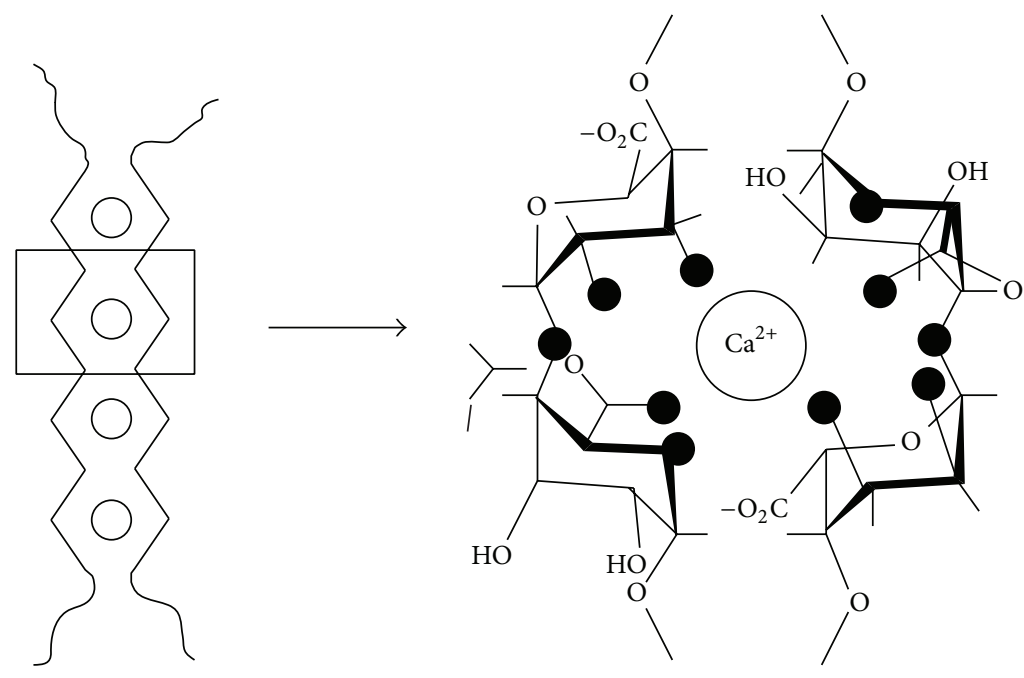

FIGURE 3: Schematic drawing and calcium coordination of the "egg-box" model, as described for the pair of guluronate chains in calcium ALG junction ones. Dark circles represent the oxygen atoms involved in the coordination of the calcium ion. Reproduced from [31] with the permission of the American Chemical Society.

very relevant because they would support the use of ALG by different parenteral routes (e.g., intra-articular). At the same time, it should be stressed that ALG has not been approved yet for parenteral administration. The development of an ultrapurified low endotoxin ALG could pave the way to applications with stricter biocompatibility demands [61].

Due to the hydrophilic nature of ALG, the release of encapsulated drug payloads could follow different mechanisms. Water-soluble drugs are mainly released by diffusion, while poorly water soluble drugs by matrix erosion. The release of small molecules is fast due to the fact that swelled
ALG matrices display a pore diameter of approximately $5 \mathrm{~nm}$ [54]. However, different modifications can be pursued to physically or chemically bind the drug to the network and to prolong the release. An additional interesting feature of ALG is that dry systems are mucoadhesive, prolonging the residence time and the release in different mucosal tissues such as intestine, lung, nose, and eye [62-67]. Due to the high chemical functionality (two $-\mathrm{OH}$ and one $-\mathrm{COOH}$ per repeating unit), the chemical modification of the side chain of ALG has been extensively explored to increase its solubility in aprotic solvents $[27,68]$, to modify other physicochemical 


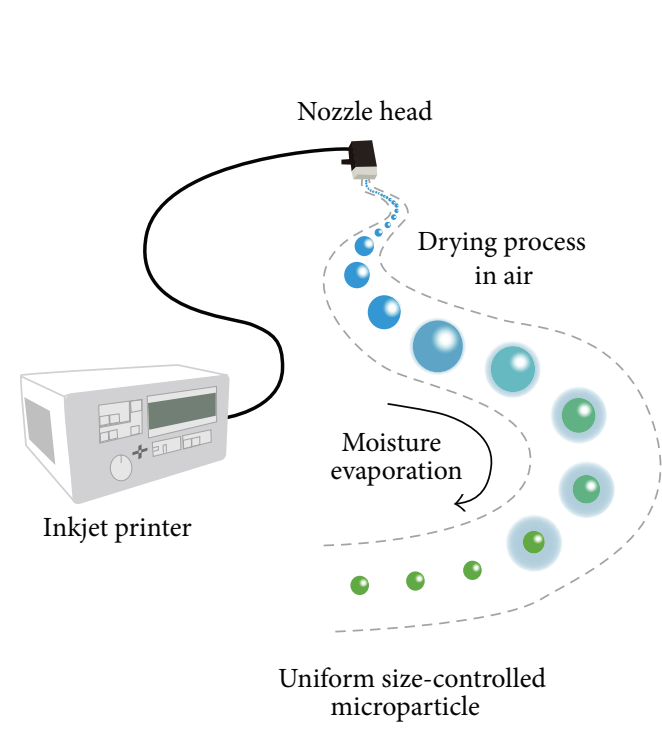

(a)

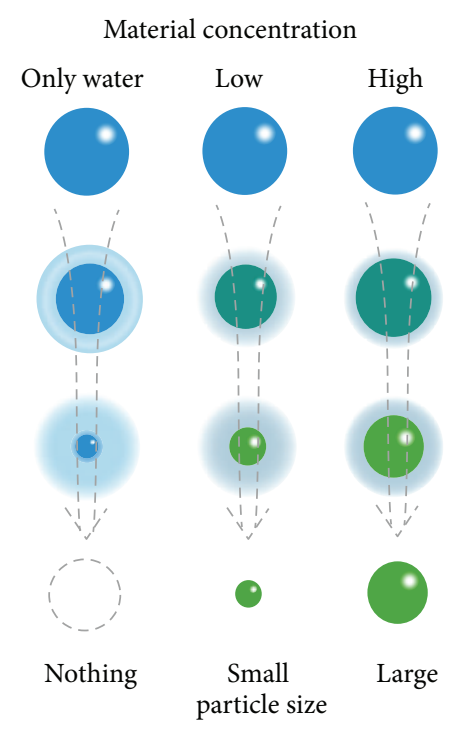

(b)

Figure 4: Concept for the production of uniform size-controlled microparticles with inkjet printer. (a) Microparticles are easily fabricated by evaporating moisture in air, and (b) size of particles could be controlled with changing the concentration of the biomaterial. Reproduced from [86] with permission of Elsevier.
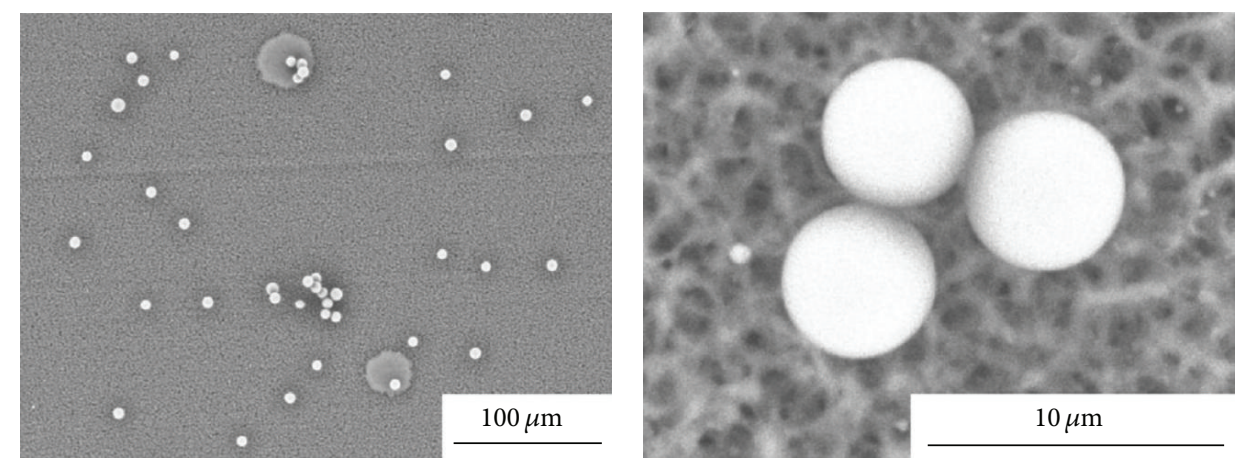

FIGURE 5: SEM micrographs of ALG microparticles fabricated by inkjet/drying using a $0.8 \%$ ALG solution. Reproduced from [86] with permission of Elsevier.

properties $[69,70]$, to attain biomimetic [71] and amphiphilic features [72], and to conjugate cell signalling ligands [73, 74]. For an extensive and thorough overview of the chemical modification of ALG, the readers are referred to the review of Pawar and Edgar [22].

\section{Alginate Applications in Oral Drug Delivery}

ALG has been employed for the production of a broad spectrum of drug delivery systems. The present paper will be focused on microparticles and nanoparticles because they represent the most innovative and promising developments [32].

3.1. Alginate Microparticles. ALG microparticles $(<200 \mu \mathrm{m})$ can be produced by different techniques [75] such as air atomization [75-77], emulsification [78, 79], and complexation with counterion polymers $[80,81]$, often combined with additional technologies. More innovative methods (e.g., spray-drying [82], electrohydrodynamic atomization [83], impinging aerosols $[84,85]$, and inkjet/drying process [86]) that enable a better control of the size and size distribution have been also reported. For example, Iwanaga et al. developed an inkjet device for the fabrication of microparticles with an unprecedented size control (Figure 4) [86]. The precise adjustment of the parameters led to very low size distributions, optimal for scale up purposes in pharmaceutical development (Figure 5) [86].

Other methods that provide very good control of the size are electrostatic droplets combined with external ionotropic gelation [87] and nebulization/gelation [88]. These technologies have been used for the encapsulation of cells, drugs, and proteins owing to the mild conditions required. A main disadvantage of calcium-crosslinked ALG is low mechanical stability that results in fast drug release. Thus, ALG microparticles are usually coated with polycationic polymers 
such as chitosan and poly-L-lysine that reduce swelling and increase their mechanical integrity in biorelevant media [8991]. As mentioned above, the use of ALG for the systemic and localized delivery by the oral route has increased over the years. In this framework, intestinal and colonic release emerged as the most intensively investigated ones. For example, Coppi et al. produced ALG microparticles of diameter smaller than $3 \mu \mathrm{m}$ by spray-drying for uptake of $M$ cells of the Peyer's patches and the targeting of polymixin B to the Gut Associated Lymphoid Tissue [92]. Particles were crosslinked with chitosan and calcium and they were gastroresistant. More recently, Urbanska et al. encapsulated oxaliplatin, a slightly soluble antitumoral drug, within chitosan-coated ALG microparticles for oral administration in colorectal cancer [91]. This formulation significantly prolonged the survival of $\mathrm{C} 57 \mathrm{BL} / 6 \mathrm{~J}-\mathrm{Apc}^{\mathrm{Min} /+}$ mice with respect to blank microparticles (Figure 6). The study was complemented with histopathology, where the different gastrointestinal compartments were stained with hematoxylin and eosin. Control groups showed tubular adenomas that protruded into the colon lumen and polypoid adenomas in the small intestine, while the oxaliplatin groups showed microadenomas (Figure 7) [91]. Surprisingly, the effect of free oxaliplatin nanoparticles was not assessed. This animal subset would have been of relevance to confirm whether the prolonged survival exclusively relied on the drug or, conversely, on the mucoadhesive drug delivery system employed for its administration and localized release. Within the same conceptual framework, Mladenovska and collaborators have developed ALG microparticles loaded with 5-aminosalicylic acid that were crosslinked and coated with calcium and chitosan employing a spray-drying technique for application in inflammatory bowel disease [93]. An interesting aspect of this study was the confirmation that the drug undergoes amorphization during the production process. This is critical to ensure its fast dissolution in the intestinal tract. Also, by using fluorescently labeled ALG and chitosan, the distribution of both polysaccharide components in the microparticles was elegantly shown (Figure 8) [93]. These results confirmed that the chitosan coating was restricted to the surface of the microparticle and it did not penetrate the matrix. ALG microspheres prepared by the emulsification technique have been also assessed for the encapsulation of more complex and sensitive payloads such as the tetanus toxoid intended for mucosal immunization [94]. The size of the microparticles was $1.34 \mu \mathrm{m}$ with very smooth surface and low surface porosity. The encapsulation efficiency reached almost 50\% and the burst effect was relatively low. Furthermore, results showed that the antigenicity was conserved in $91 \%$ with respect to the free toxoid.

Another strategy to improve the mechanical stability of ALG matrices in aqueous media is by blending it with polycationic polymers (e.g., chitosan, pectin, gelatin) to form polyelectrolyte complexes. Jaya et al. encapsulated aspirin within ALG/pectin microspheres $(90 \mu \mathrm{m})$ by means of a homogenization/atomization and calcium crosslinking method and assessed the effect of the composition on the release kinetics [95]. The release was slow and controlled in

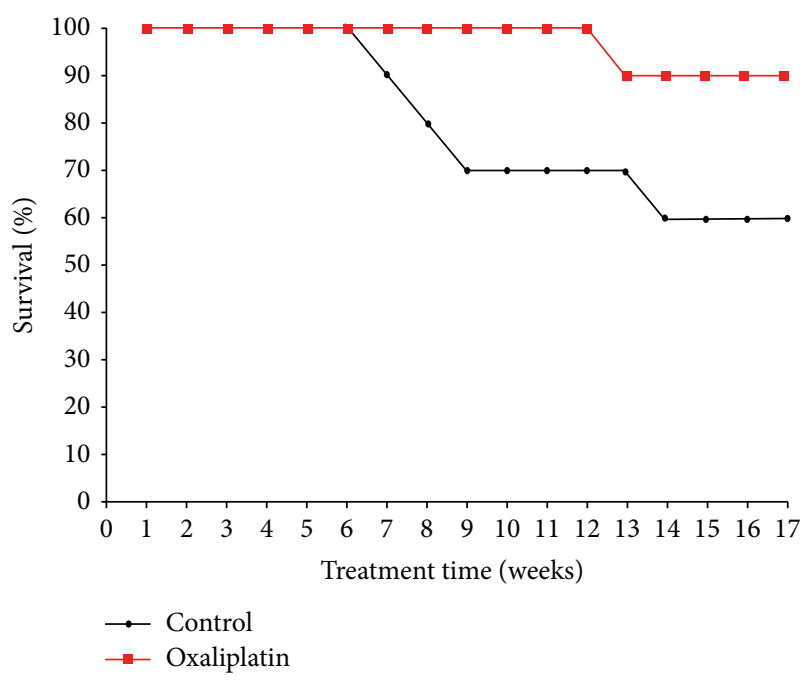

Figure 6: Animal survival profile over 17 weeks. Control group animals gavaged with drug-free ALG-chitosan microcapsules suspended in PBS and treatment group animals gavaged with microencapsulated oxaliplatin nanoparticles suspended in PBS. Reproduced from [91] with permission of Elsevier.

the $\mathrm{pH}$ range between 1.2 and 8.2, what covers the conditions of the gastrointestinal tract. In addition, an increase of the pectin content increased the release rate. These results shed light on the versatility of ALG and the ability to fine tune the (bio)pharmaceutic performance by changing production methods and qualitative and quantitative compositions.

Encapsulation can be also used to prevent noxious effects of the encapsulated drug on the gastrointestinal mucosa, such as the ulcerogenicity of diclofenac sodium and other nonsteroidal anti-inflammatory drugs [96].

Another method to produce drug-loaded ALG microparticles is to use drug microcrystals as template to produce polyelectrolyte multilayers or to directly coat them with ALG $[97,98]$. In the case of multilayered systems, ALG is combined with a polycationic polymer and both layers are deposited following an alternated pattern [97]. An advantage of this technique is the very fine control of the capsule thickness, the microparticle diameter, and the release rate. At the same time, it should be pointed out that this approach is more laborious than more conventional ones where the properties of the final system can be adjusted by changing parameters such as drug/polymer ratio, molecular weight of the polymeric components, the concentration of the counterionic polymer and calcium ions in the hardening medium, and the hardening time [99]. In fact, multilayered coating appears as less feasible to scale up and translate into clinics than common processing methods. This is the reason why most of the works were devoted to modify and optimize standard technologies rather than explore more sophisticated and less reproducible ones. In this framework, Makai et al. used spray-drying for coating pure trandolapril microparticles with ALG, results being acceptable [98]. However, part of the drug remained nonencapsulated, as apparent from SEM analysis (Figure 9) [98]. This is a very common phenomenon 


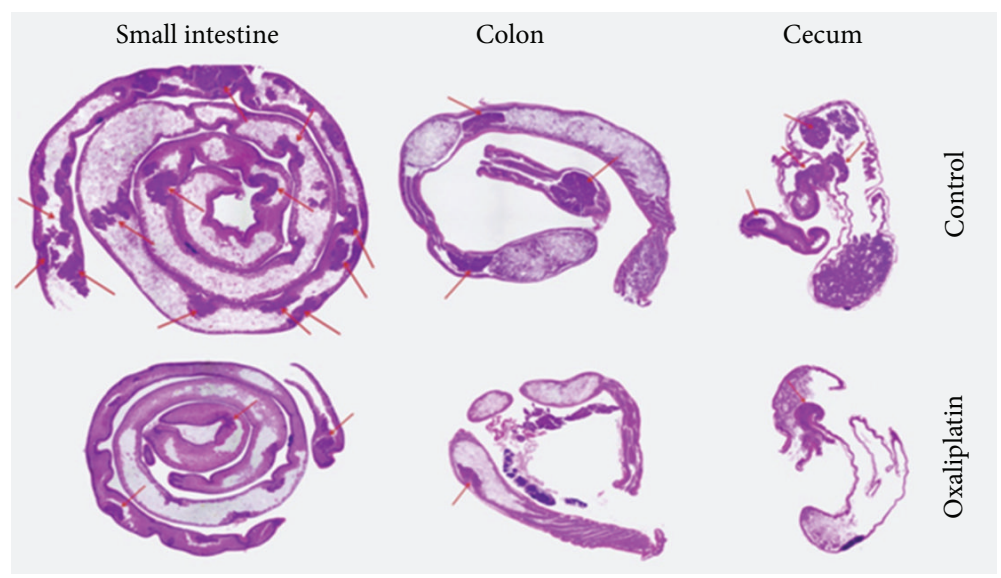

Figure 7: Hematoxylin and eosin tissue staining of mice polyps in small intestine, colon, and cecum for control and oxaliplatin treatment groups. Control mice had a higher number of polyps, indicated with red arrows, in the small intestine, colon, and cecum compared with oxaliplatin treatment group. Reproduced from [91] with permission of Elsevier.

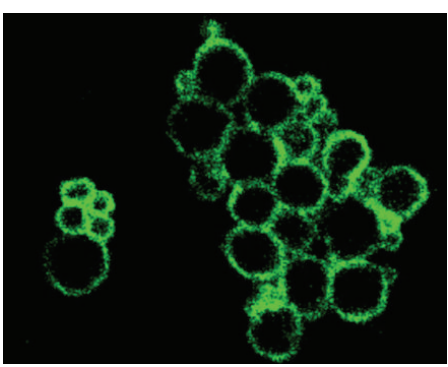

(a)

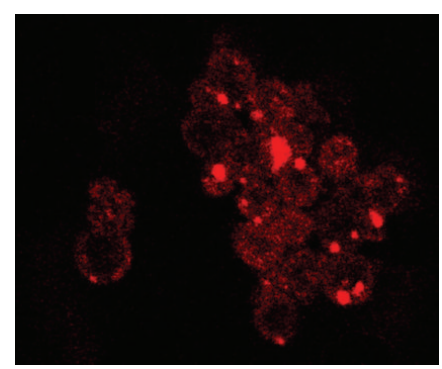

(b)

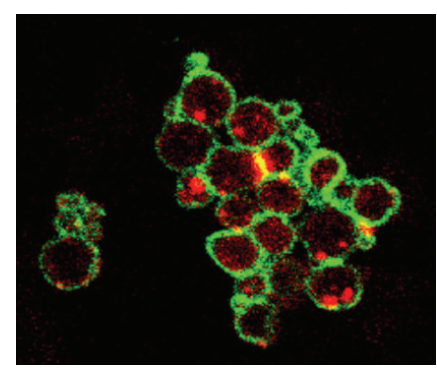

(c)

FIGURE 8: Confocal laser scanning microscopy of 5-aminosalycilic acid-loaded chitosan-Ca-ALG microparticles. (a) Fluorescein isothiocyanate-labeled chitosan (green), (b) rhodamine isothiocyanate-labeled ALG (red), and (c) image obtained by superposition. Reproduced from [93] with permission of Elsevier.

when the interaction between the drug and the matrix is not sufficiently strong or when the morphology of the drug particles is nonspherical (e.g., needle-like) and they disrupt the microparticle surface. To overcome this disadvantage, particles could be film-coated with polymers that provide an integral outer surface layer. Aiming to improve the transport across the intestinal epithelium of the water-soluble antibiotic gentamicin, Iannuccelli et al. used a different approach [100]. The cationic drug was initially complexed with the polyanionic ALG, and then ALG was crosslinked with chitosan and calcium ions. Microparticles were translocated via $\mathrm{M}$ cells and follicle associated epithelium of the Peyer's patches and enterocytes, as demonstrated in ex vivo perfusion assays with rabbit and rat intestine containing Peyer's patches and in vitro in a Caco-2 cell monolayer model. However, only M cells transported the microparticles to subepithelial regions. This is a very interesting result and suggests the possible saturation of this transport pathway. The same group explored a similar drug delivery system to target the antitumoral tamoxifen to the lymphatic system [101].

The fast release of the encapsulated drugs is a relevant drawback of ALG. To stabilize the matrix and sustain the release, microparticles could be also obtained by forming interpenetrated polymer networks of ALG with other polysaccharides and natural polymers that are crosslinked ionotropically and/or covalently with different coupling agents [63, 102-104]. The later stage enables a better control of the matrix porosity and swelling and mechanical properties and consequently of the release rate. In this framework, Kulkarni and coworkers developed interpenetrating network beads made of ALG, gelatin and egg albumin that were crosslinked with glutaraldehyde to increase the half-life of the antibiotic cefadroxil [105]. The encapsulation efficiency was as high as $88 \%$ and the burst release was relatively low. Moreover, the release was sustained for at least $7 \mathrm{~h}$.

ALG blends with cellulose derivatives, poly(acrylate)s, and pristine and modified polysaccharides have been also investigated. For example, Babu et al. prepared ALG/ methylcellulose spherical microparticles by a water-in-oil emulsion method, crosslinked them with glutaraldehyde, and loaded them with nifedipine [106]. The drug was dispersed at the molecular level and the release was controlled for over $12 \mathrm{~h}$. In another kind of application, the same research group used a similar system for the release of a organophosphate 


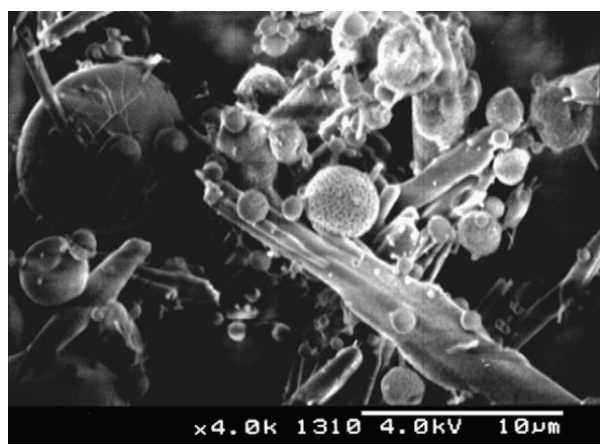

(a)

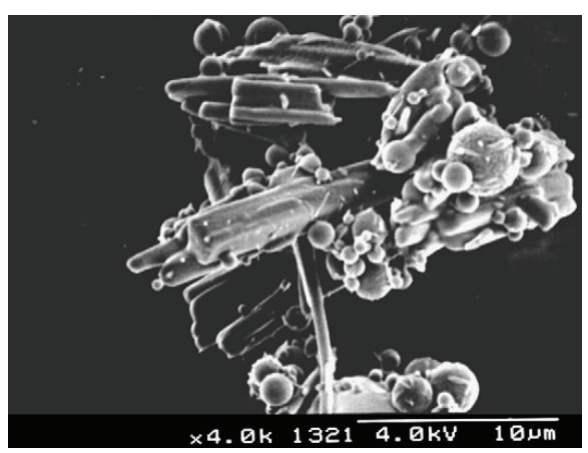

(b)

FIGURE 9: SEM micrograph of tandolapril-loaded ALG microparticles. The drug payload was $50 \%$ of the dry weight. (a) Microparticles without lactose and (b) microparticles with lactose. Scale bar $=10 \mu \mathrm{m}$. Reproduced from [98] with permission of Elsevier.

insecticide [107]. Angadi et al. produced blend microbeads of ALG and sodium carboxymethyl cellulose and coated them with chitosan for the controlled release of amoxicillin in the stomach to treat the infection by Helicobacter pylori [108]. The size was between 745 and $889 \mu \mathrm{m}$, the upper limit for a microparticle, though this example is described because it addressed gastric release as opposed to a majority of works that focus on the intestinal one. In addition, the encapsulation efficiency was in the $52-92 \%$ range. The coating reduced the burst effect and sustained the release over more than $8 \mathrm{~h}$ under gastric-like $\mathrm{pH}$ conditions following an anomalous release kinetics. A limitation of this work is that it did not report on the drug concentrations attained and whether they were or were not within the therapeutic concentration. Mennini et al. developed ALG/chitosan microspheres for colonic delivery of celecoxib- $\beta$-cyclodextrinpolyvinylpyrrolidone complex in two kinds of therapy: (i) systemic in chronotherapic treatment of arthritis and (ii) local in prophylaxis of colon carcinogenesis [109]. Another inhibitor of the cyclooxygenase-2 enzyme, valdecoxib, was also encapsulated within Eudragit S100 and sodium alginate microparticles for colonic release [110]. More recently, $\mathrm{pH}$ and thermoresponsive microspheres of ALG and poly $(N-$ isopropylacrylamide)-g-guar gum were obtained by emulsion coupled to chemical crosslinking with glutaraldehyde to encapsulate the antituberculosis drug isoniazid [111]. The release was sustained for at least $12 \mathrm{~h}$ with a strong dependence on the $\mathrm{pH}$ of the medium; the release increased at $\mathrm{pH} 7.4$ with respect to 1.2. Furthermore, the incorporation of graft copolymer enabled a much better control of the release kinetics with a substantial decrease of the burst effect. The modulation of the release using external stimuli (e.g., electrical current) has also been explored, though not in the case of particles but of macroscopic hydrogels [112].

Embedding of ALG microparticles within monolithic structures such as hydrogels has been also assessed to reduce the burst effect. For example, Zhu et al. encapsulated the natural drug berberine hydrochloride within ALG microspheres using an emulsification/gelation method and then entrapped them into carboxymethyl chitosan hydrogels to produce a new drug delivery composite system [113]; particles increased the hydrogel compression strength. Another interesting strategy was the production of core-shell ALG microbeads coated with self-assembled porous $\mathrm{CaCO}_{3}$ microparticles (Figure 10) [114]. This novel drug delivery system was named colloidosome and it reduced the release rate of a water-soluble model drug, brilliant blue, due to the generation of a dense superficial layer of a ceramic material. The same group developed colloidosomes formed by an ALG core and a $\mathrm{Fe}_{2} \mathrm{O}_{3}$ shell [115].

The oral administration of peptides and proteins without detrimental effects due to fast release and degradation of the payload in the aggressive gastrointestinal fluids is one of the challenges of contemporary pharmaceutical development. Their encapsulation usually demands more intense studies owing to the fact that production processes need to be mild and maintain their structure and function unaltered. Also, compositions are more complex and usually incorporate various polymers to enhance the encapsulation efficiency. Yu et al. reported on composite $\mathrm{pH}$-sensitive microparticles of ALG, chitosan, and pectin for the encapsulation of bovine serum albumin as a model protein [116]. The method was shredding and combined tripolyphosphate crosslinking of chitosan, electrostatic complexation by ALG and/or pectin with chitosan, and ionotropic gelation of ALG with calcium ions. The release at $\mathrm{pH}$ values of 1.2 and 5.0 was substantially slower than at 7.4, supporting the potential of this system for specific oral delivery. In another work, Chen and coworkers developed novel poly(L-histidine)-chitosan/alginate complex microcapsules for the encapsulation of haemoglobin as model protein [117]. Microparticles were spherical and with narrow size distribution and smooth surface. The encapsulation efficiency was above $85 \%$ and the protein payload as high as $40-48 \%$. In addition, the release followed first-order kinetics with released amounts between $72 \%$ and $87 \%$ after $72 \mathrm{~h}$ in $\mathrm{PBS}$ of $\mathrm{pH}$ 6.8. The main parameter affecting the performance of the microparticles was the molecular weight of chitosan that was used in a concentration of $0.05 \%$. To improve the deliverability of $\alpha$-interferon by the oral route without degradation, Saez et al. microencapsulated it within 


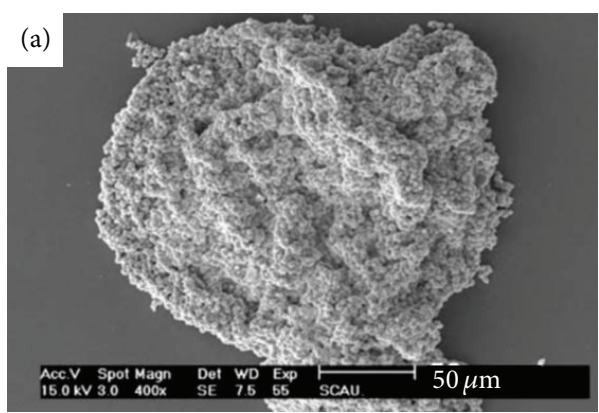

(a)

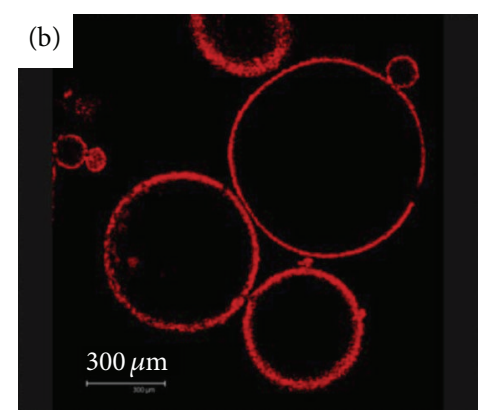

(b)

FIGURE 10: Morphology of the colloidosomes. (a) SEM and (b) confocal laser scanning microscopy; $\mathrm{CaCO}_{3}$ microparticles were modified with rhodamine isothiocyanate for red fluorescence visualization. Reproduced from [114] with permission of Elsevier.

ALG microspheres [118]; interferons are usually injected and this approach would represent a breakthrough in the immunotherapy with this immunomodulatory, antiproliferative, and antiviral agent.

Due to the chronic nature of the treatment of diabetes that entails painful and stressful frequent injections and the great morbidity of the disease in the developed world, insulin appears as one of the most appealing proteins to investigate novel drug delivery systems of administration by nonparenteral routes. In this context, Neufeld and collaborators have devoted efforts to develop different platforms for oral insulin [30, 119-122]. Employing an emulsion/internal gelation method, they produced small insulin-loaded ALG microparticles $(<10 \mu \mathrm{m})$ with high encapsulation efficiency [30]. To improve the recovery, a centrifugation and dehydration process was implemented. The stability of insulin in the gastric medium was also increased by reinforcing ALG microparticles with chitosan and dextran sulfate [123]. A similar concept was followed by Zhang et al. that also assessed glycemia levels in streptozotocin-induced diabetic rats with promising results (Figure 11) [124]. Glucose levels were maintained at a minimum level over $72 \mathrm{~h}$ as opposed to free insulin. The maintenance of constant low glucose plasma concentrations is critical to prevent the development of complications and the organic deterioration associated with the disease [125]. Another approach was the reencapsulation of bovine insulin-loaded ALG particles within poly(lactic-coglycolic) acid microparticles [126]. Composite microparticles showed a diameter of approximately $22 \mu \mathrm{m}$ and a porous surface and they sustained the release over 130 days. Thus, these systems are more promising for parenteral than for oral administration. Other proteins that have been encapsulated within ALG microparticles include the proteases papain [127] and subtilisin [128]. More recent works have also explored the encapsulation of other sensitive biologicals such as adenoviruses [129] and plasmid DNA (pDNA) [130], though their application is not always envisioned for oral administration. For example, Nograles et al. encapsulated a mammalian expression vector bearing a green fluorescent protein (GFP) reporter gene within ALG microparticles with a diameter of $40-60 \mu \mathrm{m}$ and administered them to mice. Green fluorescence was detected in intestinal cells

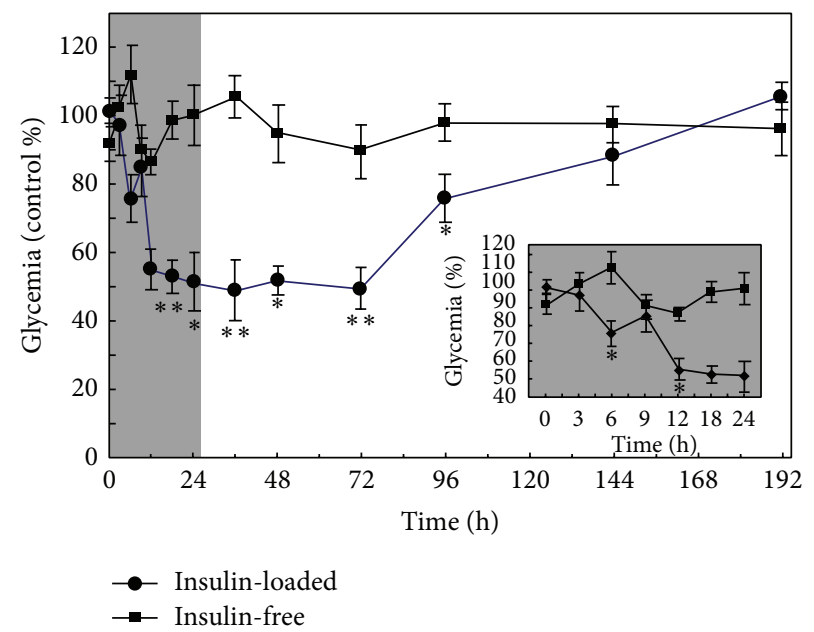

FIGURE 11: Serum glucose concentration after oral administration of insulin-free and insulin-loaded (100 IU/kg) ALG-chitosan microspheres to streptozotocin-induced diabetic rats. Statistically significant difference from insulin-free microspheres: ${ }^{*} P<0.05$ and ${ }^{* *} P<0.01$. Reproduced from [124] with permission of Elsevier.

(Figure 12) [130]. While ALG has been mainly used as the major component of the microparticle matrix, other studies assessed the performance of ALG as a coating agent to protect and sustain the release of encapsulated payloads and to confer mucoadhesiveness. The protective nature of ALG in the stomach stems from its reduced solubility at low $\mathrm{pH}$ values due to the protonation of the pendant carboxylic moieties [21, 33, 131]. For example, Li et al. developed bovine serum albumin-loaded chitosan microparticles and coated them with ALG using the layer-by-layer method [132]. This modification significantly reduced the burst effect and prevented the degradation of the model protein in $0.01 \mathrm{M} \mathrm{HCl}$ for $2 \mathrm{~h}$, suggesting that it would stabilize it during the gastric transit.

Another advantage of ALG is related to its ability to efficiently encapsulate hydrophilic and hydrophobic drugs [133-138]. It should be stressed though that in the case of hydrophilic drugs, ionotropic gelation is not feasible due 


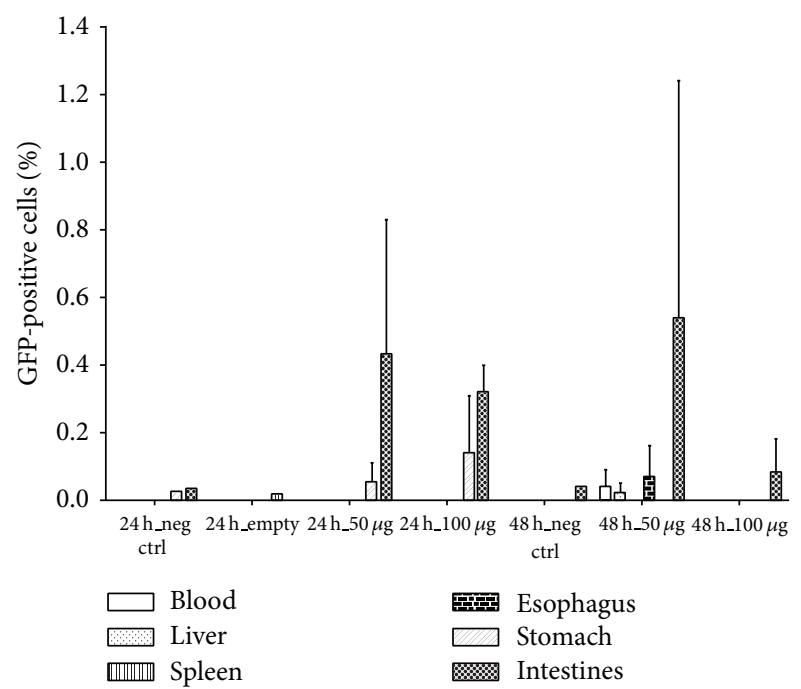

(a)

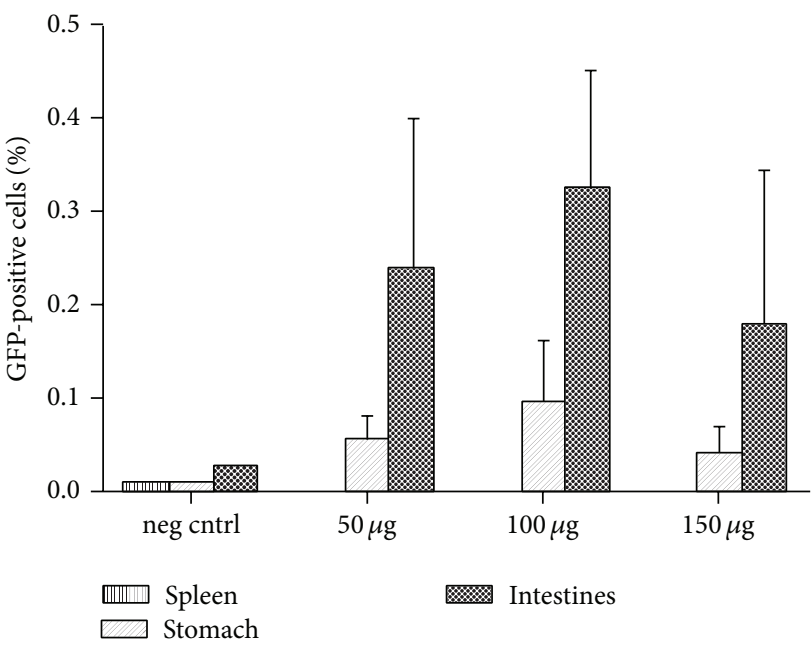

(b)

FIGURE 12: Oral delivery of pDNA with GFP reporter in ALG microspheres in mice. (a) Flow cytometric analyses showing biodistribution reflected through \%GFP-positive cells among various organs 24 and $48 \mathrm{~h}$ after the administration of $50 \mu \mathrm{g}$ and $100 \mu \mathrm{g}$ pDNA dose. Number of animals for each dose group $=3$; total number of mice $=15$. (b) Dose-response assessment showing \%GFP-positive cells among various mice organs $24 \mathrm{~h}$ after the administration of $50 \mu \mathrm{g}, 100 \mu \mathrm{g}$, and $150 \mu \mathrm{g}$ dose. Number of animals for each dose group $=6$ (except for $150 \mu \mathrm{g}$-dose group which had only 3 ); total number of mice $=18$. All measurements were done in triplicates. Results represent mean \pm standard error with the basal levels of expression from negative controls subtracted from expression levels observed in dosed groups. Reproduced from [130] with permission of Elsevier.

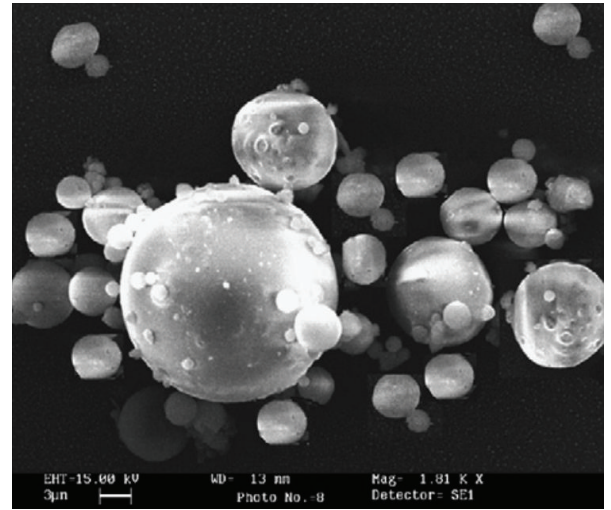

FIGURE 13: Isoniazid-loaded ALG microparticles obtained by a simple emulsion method. Reproduced from [133] with permission of Elsevier.

to very low encapsulation efficiency that stems from the fast escape of the drug to the crosslinking medium. In this context, the methodology needs to be conveniently modified. Rastogi et al. studied the encapsulation of isoniazid, a firstline antituberculosis water-soluble drug, for enteric release employing an emulsion technique [133]. On the one hand, the encapsulation efficiency was $91 \%$. On the other, the relatively high viscosity of ALG solutions jeopardized the production of products with narrow size distribution (Figure 13) [133]. This is a drawback when compared to the ability of more complex techniques to render more uniform size populations. Conversely, hydrophobic drugs can be incorporated in the form of small crystals homogeneously dispersed in the ALG matrix, as reported for the hypoglycemic drug gliclazide [134] and the anti-inflammatory prednisolone [138], or encapsulated within nanoparticles of a hydrophobic polymer (e.g., poly(lactide)) and then reencapsulated within ALG, as shown for silymarin [137]. The dispersion of poorly water-soluble drugs (e.g., nateglinide) in ALG using organic solvents has been also pursued, though the fast release is probably anticipated [139].

ALG encapsulation could be also exploited to improve the pharmacokinetics of drugs displaying a relatively short half-life. For example, Abdelbary et al. encapsulated the antidiabetic drug glipizide within pure ALG microparticles and combinations with chitosan or poly(acrylic acid) [140]. Due to a sustained release, the $t_{1 / 2}$ was extended from 4 to $9 \mathrm{~h}$.

The good cytocompatibility of ALG has been also assessed for the encapsulation of probiotic bacteria (e.g., Lactobacillus acydophilus, Bifidobacterium lactis) that are sensitive to gastric fluids [141]. Incorporation of xanthan gum (0.5\%) as a 
hydrophilic retardant polymer or cellulose acetate phthalate (1\%) as a gastroresistant polymer to $3 \%$ ALG microparticles increased bacterial survival from $63 \%$ to $76 \%$. Moreover, when the standard production technique was replaced by an atomization one, the size of the particles was reduced and the survival increased up to $91 \%$ after $24 \mathrm{~h}$ in gastric-like medium.

Other works exploited the properties of ALG matrices to develop novel biosensing, imaging, and diagnosis tools, though these developments are mainly envisioned as external or implantable devices and not for oral administration [142-144]. Following the revolution in therapeutics led by nanotechnology, the production of ALG nanoparticles for oral drug administration has also emerged as an appealing technology platform. The following section will address this specific research avenue.

3.2. Alginate Nanoparticles. Nanotechnology has opened new possibilities to control and manipulate the matter. From a biomedical perspective, it enabled capitalization on novel properties of biomaterials to enhance the prevention, diagnosis, and treatment of disease and led to the emergence of the new field of theranostics $[10,11,145]$. Based on the successful experience of ALG microparticles, the study of ALG nanoparticles was expected to gain impulse due to the benefit of particle size reduction to reach cellular and subcellular structures in the gastrointestinal epithelium and subepithelial dome regions that are relevant for mucosal vaccination [146] and drug transport to the blood stream [147]. However, as opposed to chitosan, another mucoadhesive polysaccharide that has been mainly used to develop nanoparticles, the literature on ALG nanoparticles is relatively scarce. One of the challenges was the modification of production methods to achieve such small sizes. For example, the conventional ionotropic crosslinking with calcium ions was usually modified [148, 149] or replaced by water-in-oil nanoemulsions $[150,151]$ and polyelectrolyte approaches with chitosan $[152,153]$. To overcome this, researchers also used other nanocarriers as templates (e.g., chitosan nanoparticles, liposomes) that were further surface-modified with ALG to confer mucoadhesiveness $[154,155]$. For example, Haidar and coworkers produced core-shell hybrid nanoparticles by the layer-by-layer assembly of ALG and chitosan on liposomes for the delivery of a growth factor [155]. Conversely, Hong and collaborators used the core of liposomes with a high bilayer melting temperature as reaction vessels to template the assembly of ALG [156]. In this context, ALG was encapsulated in the liposomal core and exposed to a calcium chloride solution at a temperature above the melting point of the bilayer. This enables the passage of calcium ions into the core and the gradual gelation of ALG. Then, the liposome was removed with surfactants to give place to $120-200 \mathrm{~nm}$ nanoparticles ALG. The process is presented in Figure 14 [156]. As mentioned above, pure drug crystals could also be used to assemble polyelectrolyte layers. Following this rationale, artemisinin nanocrystals $(766 \mathrm{~nm})$ were coated with chitosan, gelatin, and ALG [157]. Following the trend presented with microparticles, a major part of the research at the interface of nanotechnology and
ALG for oral administration was devoted to insulin [158160]. At the same time, some isolated studies explored this platform for the encapsulation of other drugs [161, 162] and antigens [163]. Ahmad et al. encapsulated the antifungal drugs clotrimazole and econazole and the antituberculosis drugs rifampicin, ethambutol, isoniazid, and pyrazinamide within ALG nanoparticles $[149,164,165]$ by means of a modified cation induced controlled gelification $[149,166]$. After oral administration, free drugs were detectable for only 6-24 h, while the encapsulated ones between 8 and 15 days. Moreover, eight doses of econazole-loaded nanoparticles had an antibacterial effect similar effect as 112 twice-a-day doses of the free drug [165]. The findings confirmed the ability of ALG nanoparticles to cross the intestinal barrier and reach the blood stream, as opposed to microparticles that are mainly retained in the gut mucosa. This beneficial effect was also investigated to develop mucopenetrating ALG/chitosan nanoparticles for the release of amoxicillin in the treatment of the infection by Helicobacter pylori, a pathogen that colonizes the deep gastric mucosa lining [166]. Results indicated lower mucoadhesiveness for the combination, though greater mucopenetration, than pure chitosan. These observations were in agreement with a study by Chen et al. that showed the enhanced permeation of bovine serum albumin-loaded $N$-trimethyl chitosan (TMC) nanoparticles across Caco 2 cell monolayers, when modified with ALG (Figure 15) [167]. This improvement would stem from an increased transcellular pathway, while the paracellular one remained unaltered [168]. Another mechanism behind this phenomenon would be the active uptake of these nanoparticles by Peyer's patches [168].

Aiming to develop an oral vaccine against schistosomiasis, a neglected parasitic disease, the Smrho protein was encapsulated within chitosan nanoparticles coated with ALG [169]. Due to its good chemical flexibility, some works addressed the chemical modification of ALG to confer gene transfection capacity $[150,170]$ or active targeting properties [168]. In this context, ALG nanoparticles loaded with the fluorescent probe protoporphyrin IX were modified with 5-aminolevulinic acid, a ligand that is selectively recognized by cancerous cells that over-express the folic acid receptor, to confer diagnostic capability by endoscopy [168]. Nanoparticles were endocytosed by colorectal cancer cells and the probe was released to the intracellular space and accumulated for sensitive photodynamic detection. These results, together with previous evidence of the performance of ALG for drug encapsulation and release support it as a valuable tool for the design of more complex systems in the emerging field of theranostics. At the same time, further studies will need to be addressed to capitalize on this potential and extend the applications of ALG.

\section{Conclusions and Perspectives}

Owing to very good biocompatibility and approval by the US-FDA as food additive, ALG has gained a preferential place among pharmaceutical excipients for the development of advanced drug delivery systems for mucosal administration. The greater interest of the scientific community 


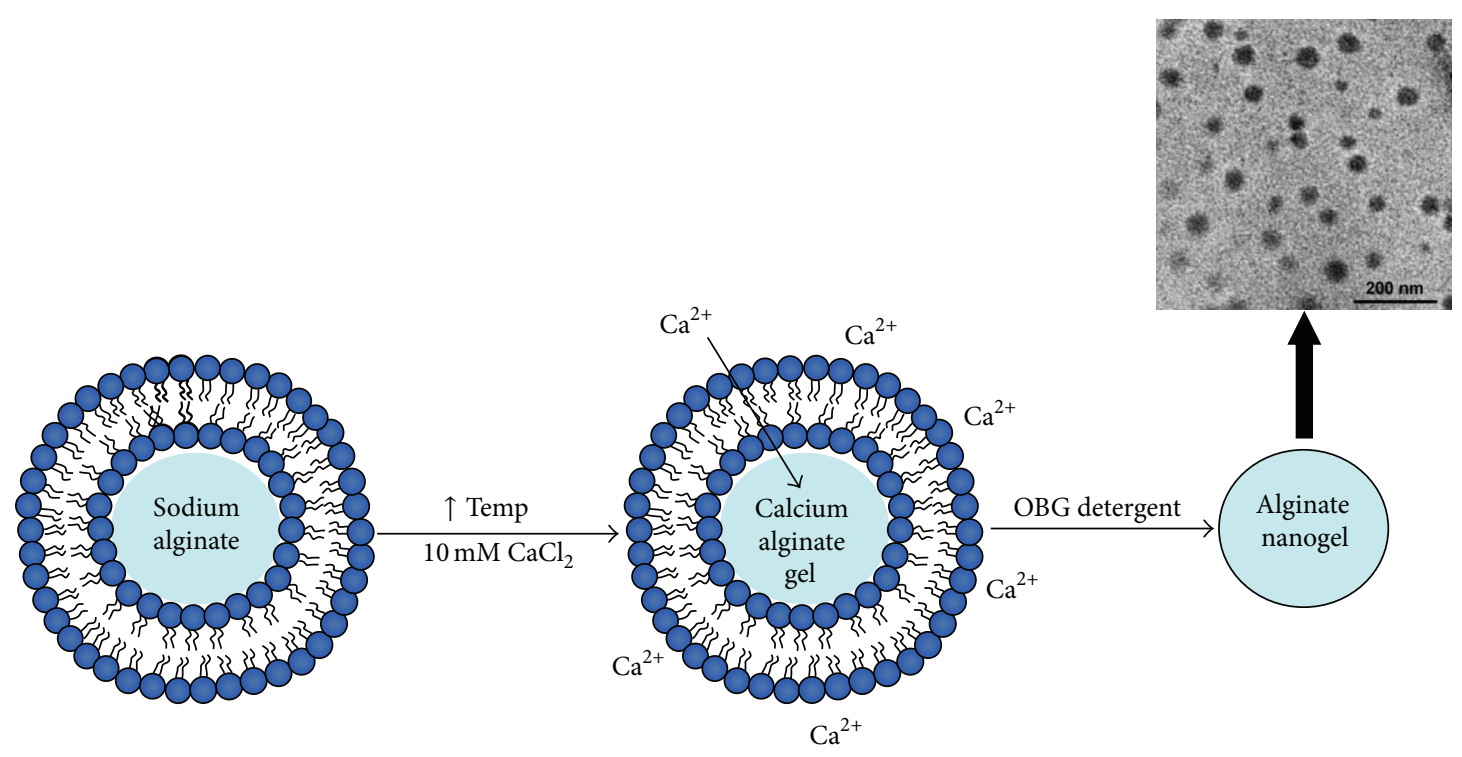

FIGURE 14: Production of ALG nanoparticles using liposomal templates. Reproduced and adapted from [156] with permission of the American Chemical Society.

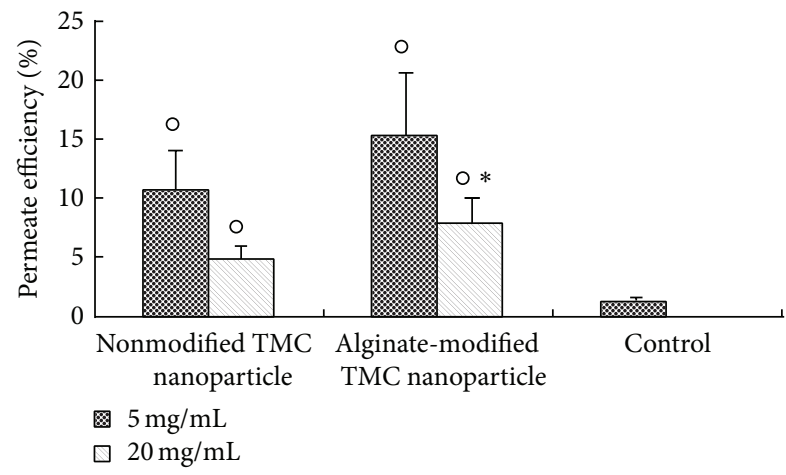

FIGURE 15: Observed permeate efficiency of bovine serum albuminloaded TMC nanoparticles, ALG-modified TMC nanoparticles at low $(5 \mathrm{mg} / \mathrm{mL})$ and high concentration $(20 \mathrm{mg} / \mathrm{mL})$, and control (bovine serum albumin solution) using Caco-2 cell monolayer. Circles indicated permeate efficiency that was significantly higher $(P<$ $0.01)$ than that of the control. Asterisks indicated permeate efficiency that was significantly higher $(P<0.05)$ than that of nonmodified TMC nanoparticles. No significant difference was observed between nonmodified and ALG-modified TMC nanoparticles at $5 \mathrm{mg} / \mathrm{mL}$. All data are mean \pm S.D. $(n=4)$. Reproduced from [168] with permission of Elsevier.

in ALG coincided with the revolution in therapeutics led by nanomedicine. This together with a great versatility to conduct fine chemical modifications and to tailor specific features by combining it with other natural and synthetic polymers have sustained the steady increase of the research at the interface of ALG and microparticles and nanoparticles during the last decade. At the same time, it should be stressed that strict isolation and purification protocols are demanded to ensure low concentrations of endotoxins and immunogenic residues and the interbatch reproducibility. These issues are even more critical to extend the use of ALG to parenteral administration routes. The present spotlight review overviewed the most recent works of ALG as a technology platform to develop microparticles and nanoparticles for oral drug delivery. The most outstanding features are mucoadhesiveness and mucopenetration that increase the passage of drug payloads through the gastrointestinal epithelium. This could be capitalized to enhance local and systemic delivery, increase oral bioavailability, and prolong release. Research on ALG microparticles has been more profuse with a broad spectrum of production methods that range from simple ionotropic gelation to more complex equipment to control size and size distribution and to ensure reproducibility and scale up. Conversely, the research of ALG nanoparticles has been limited to a few payloads, insulin being the most intensively assessed. In any event, ALG bears a great potential and its more extensive implementation in the development of innovative nanodrug delivery systems with translation potential is a matter of time.

\section{Conflict of Interests}

The author declares that there is no conflict of interests regarding the publication of this paper.

\section{References}

[1] D. Q. M. Craig, "Pharmaceutical materials science-resuscitation or reincarnation?" Journal of Pharmacy and Pharmacology, vol. 49, no. 2, pp. 119-126, 1997.

[2] Y. Cui, "A material science perspective of pharmaceutical solids," International Journal of Pharmaceutics, vol. 339, no. 1-2, pp. 3-18, 2007. 
[3] C. C. Sun, "Materials science tetrahedron-a useful tool for pharmaceutical research and development," Journal of Pharmaceutical Sciences, vol. 98, no. 5, pp. 1671-1687, 2009.

[4] G. L. Amidon, H. Lennernas, V. P. Shah, and J. R. Crison, "A theoretical basis for a biopharmaceutic drug classification: the correlation of in vitro drug product dissolution and in vivo bioavailability," Pharmaceutical Research, vol. 12, no. 3, pp. 413420, 1995.

[5] S. Stegemann, F. Leveiller, D. Franchi, H. de Jong, and H. Lindén, "When poor solubility becomes an issue: from early stage to proof of concept," European Journal of Pharmaceutical Sciences, vol. 31, no. 5, pp. 249-261, 2007.

[6] P. Li and L. Zhao, "Developing early formulations: practice and perspective," International Journal of Pharmaceutics, vol. 341, no. 1-2, pp. 1-19, 2007.

[7] A. Dahan, J. M. Miller, and G. L. Amidon, "Prediction of solubility and permeability class membership: provisional BCS classification of the world's top oral drugs," AAPS Journal, vol. 11, no. 4, pp. 740-746, 2009.

[8] A. F. Soares, R. D. A. Carvalho, and F. Veiga, "Oral administration of peptides and proteins: nanoparticles and cyclodextrins as biocompatible delivery systems," Nanomedicine, vol. 2, no. 2, pp. 183-202, 2007.

[9] F. P. Guengerich, "Mechanisms of drug toxicity and relevance to pharmaceutical development," Drug Metabolism and Pharmacokinetics, vol. 26, no. 1, pp. 3-14, 2011.

[10] H. Devalapally, A. Chakilam, and M. M. Amiji, "Role of nanotechnology in pharmaceutical product development," Journal of Pharmaceutical Sciences, vol. 96, no. 10, pp. 2547-2565, 2007.

[11] A. Sosnik, A. Carcaboso, and D. A. Chiappetta, "Polymeric nanocarriers: new endeavors for the optimization of the technological aspects of drugs," Recent Patents on Biomedical Engineering, vol. 1, no. 1, pp. 43-59, 2008.

[12] A. H. Shojaei, "Buccal mucosa as a route for systemic drug delivery: a review," Journal of Pharmacy \& Pharmaceutical Sciences, vol. 1, no. 1, pp. 15-30, 1998.

[13] A. Sosnik, K. P. Seremeta, J. C. Imperiale, and D. A. Chiappetta, "Novel formulation and drug delivery strategies for the treatment of pediatric poverty-related diseases," Expert Opinion on Drug Delivery, vol. 9, no. 3, pp. 303-323, 2012.

[14] D. Sathish, S. Himabindu, Y. S. Kumar, S. Shayeda, and Y. M. Rao, "Floating drug delivery systems for prolonging gastric residence time: a review," Current Drug Delivery, vol. 8, no. 5, pp. 494-510, 2011.

[15] J. Schrager, "The chemical composition and function of gastrointestinal mucus," Gut, vol. 11, no. 5, pp. 450-456, 1970.

[16] C. Atuma, V. Strugala, A. Allen, and L. Holm, "The adherent gastrointestinal mucus gel layer: thickness and physical state in vivo," American Journal of Physiology: Gastrointestinal and Liver Physiology, vol. 280, no. 5, pp. G922-G929, 2001.

[17] L. M. Ensign, R. Cone, and J. Hanes, "Oral drug delivery with polymeric nanoparticles: the gastrointestinal mucus barriers," Advanced Drug Delivery Reviews, vol. 64, no. 6, pp. 557-570, 2012.

[18] J. D. Neves, M. F. Bahia, M. M. Amiji, and B. Sarmento, "Mucoadhesive nanomedicines: characterization and modulation of mucoadhesion at the nanoscale," Expert Opinion on Drug Delivery, vol. 8, no. 8, pp. 1085-1104, 2011.

[19] A. C. Hunter, J. Elsom, P. P. Wibroe, and S. M. Moghim, "Polymeric particulate technologies for oral drug delivery and targeting: a pathophysiological perspective," Maturitas, vol. 73, no. 1, pp. 5-18, 2012.
[20] A. Bernkop-Schnürch, "Nanocarrier systems for oral drug delivery: do we really need them?" European Journal of Pharmaceutical Sciences, vol. 49, no. 2, pp. 272-277, 2013.

[21] K. Y. Lee and D. J. Mooney, "Alginate: properties and biomedical applications," Progress in Polymer Science, vol. 37, no. 1, pp. 106126, 2012.

[22] S. N. Pawar and K. J. Edgar, "Alginate derivatization: a review of chemistry, properties and applications," Biomaterials, vol. 33, no. 11, pp. 3279-3305, 2012.

[23] S. Swain, A. Behera, S. Beg et al., "Modified alginate beads for mucoadhesive drug delivery system: an updated review of patents," Recent Patents on Drug Delivery \& Formulation, vol. 6, no. 3, pp. 259-277, 2012.

[24] K. I. Draget, O. Smidsrod, and G. Skjak-Braek, "Alginates from algae," in Polysaccharides and Polyamides in the Food Industry: Properties, Production and Patents, E. A. Steinbuchel and S. K. Rhee, Eds., pp. 1-30, Wiley-VCH Verlach GmbH, Weinheim, Germany, 2005.

[25] M. Rinaudo, "Main properties and current applications of some polysaccharides as biomaterials," Polymer International, vol. 57, no. 3, pp. 397-430, 2008.

[26] O. Smidsrod and G. Skjak-Braek, "Alginate as immobilization matrix for cells," Trends in Biotechnology, vol. 8, no. 3, pp. 71-78, 1990.

[27] A. Penman and G. R. Sanderson, "A method for the determination of uronic acid sequence in alginates," Carbohydrate Research, vol. 25, no. 2, pp. 273-282, 1972.

[28] H. Grasdalen, "High-field, ${ }^{1}$ H-n.m.r. spectroscopy of alginate: sequential structure and linkage conformations," Carbohydrate Research, vol. 118, pp. 255-260, 1983.

[29] H. H. Tønnesen and J. Karlsen, "Alginate in drug delivery systems," Drug Development and Industrial Pharmacy, vol. 28, no. 6, pp. 621-630, 2002.

[30] C. P. Reis, A. J. Ribeiro, R. J. Neufeld, and F. Veiga, "Alginate microparticles as novel carrier for oral insulin delivery," Biotechnology and Bioengineering, vol. 96, no. 5, pp. 977-989, 2007.

[31] I. Braccini and S. Pérez, "Molecular basis of $\mathrm{Ca}^{2+}$-induced gelation in alginates and pectins: the egg-box model revisited," Biomacromolecules, vol. 2, no. 4, pp. 1089-1096, 2001.

[32] C. H. Goh, P. W. S. Heng, and L. W. Chan, "Alginates as a useful natural polymer for microencapsulation and therapeutic applications," Carbohydrate Polymers, vol. 88, no. 1, pp. 1-12, 2012.

[33] M. George and T. E. Abraham, "Polyionic hydrocolloids for the intestinal delivery of protein drugs: alginate and chitosan-a review," Journal of Controlled Release, vol. 114, no. 1, pp. 1-14, 2006.

[34] W. R. Gombotz and S. F. Wee, "Protein release from alginate matrices," Advanced Drug Delivery Reviews, vol. 64, pp. 194-205, 2012.

[35] J. M. Dang and K. W. Leong, "Natural polymers for gene delivery and tissue engineering," Advanced Drug Delivery Reviews, vol. 58, no. 4, pp. 487-499, 2006.

[36] S. Khormaee, O. A. Ali, J. Chodosh, and D. J. Mooney, "Optimizing siRNA efficacy through alteration in the target celladhesion substrate interaction," Journal of Biomedical Materials Research A, vol. 100, no. 10, pp. 2637-2643, 2012.

[37] W. T. K. Stevenson and M. V. Sefton, "Graft copolymer emulsions of sodium alginate with hydroxyallsyl methacrylates for microencapsulation," Biomaterials, vol. 8, no. 6, pp. 449-457, 1987. 
[38] G. Orive, S. Ponce, R. M. Hernández, A. R. Gascón, M. Igartua, and J. L. Pedraz, "Biocompatibility of microcapsules for cell immobilization elaborated with different type of alginates," Biomaterials, vol. 23, no. 18, pp. 3825-3831, 2002.

[39] J. A. Rowley, G. Madlambayan, and D. J. Mooney, "Alginate hydrogels as synthetic extracellular matrix materials," Biomaterials, vol. 20, no. 1, pp. 45-53, 1999.

[40] P. de Vos, M. M. Faas, B. Strand, and R. Calafiore, "Alginatebased microcapsules for immunoisolation of pancreatic islets," Biomaterials, vol. 27, no. 32, pp. 5603-5617, 2006.

[41] X.-W. Shi, Y.-M. Du, L.-P. Sun, J.-H. Yang, X.-H. Wang, and X.-L. Su, "Ionically crosslinked alginate/carboxymethyl chitin beads for oral delivery of protein drugs," Macromolecular Bioscience, vol. 5, no. 9, pp. 881-889, 2005.

[42] B.-H. Chueh, Y. Zheng, Y.-S. Torisawa et al., "Patterning alginate hydrogels using light-directed release of caged calcium in a microfluidic device," Biomedical Microdevices, vol. 12, no. 1, pp. 145-151, 2010.

[43] I. Machida-Sano, Y. Matsuda, and H. Namiki, "A novel harvesting method for cultured cells using iron-cross-linked alginate films as culture substrates," Biotechnology and Applied Biochemistry, vol. 55, no. 1, pp. 1-8, 2010.

[44] L. W. Chan, A. L. Ching, C. V. Liew, and P. W. S. Heng, "Mechanistic study on hydration and drug release behavior of sodium alginate compacts," Drug Development and Industrial Pharmacy, vol. 33, no. 6, pp. 667-676, 2007.

[45] D. Chang and R.-K. Chang, "Review of current issues in pharmaceutical excipients," Pharmaceutical Technology, vol. 31, no. 5, pp. 56-66, 2007.

[46] Sodium Alginate, "CFR—code of federal regulations title 21," 2013, http://www.accessdata.fda.gov/scripts/cdrh/cfdocs/cfcfr/ CFRSearch.cfm?fr=184.1724.

[47] H.-G. Choi and C.-K. Kim, "Development of omeprazole buccal adhesive tablets with stability enhancement in human saliva," Journal of Controlled Release, vol. 68, no. 3, pp. 397-404, 2000.

[48] Y. Qin, "Alginate fibres: an overview of the production processes and applications in wound management," Polymer International, vol. 57, no. 2, pp. 171-180, 2008.

[49] J. S. Boateng, K. H. Matthews, H. N. E. Stevens, and G. M. Eccleston, "Wound healing dressings and drug delivery systems: a review," Journal of Pharmaceutical Sciences, vol. 97, no. 8, pp. 2892-2923, 2008.

[50] A. Thomas, K. G. Harding, and K. Moore, "Alginates from wound dressings activate human macrophages to secrete tumour necrosis factor- $\alpha$, Biomaterials, vol. 21, no. 17, pp. 1797$1802,2000$.

[51] J. Timmons, "ActivHeal AquaFiber: a new soft, conformable highly-absorbent dressing for use with chronic wounds," Wounds UK, vol. 4, no. 3, pp. 88-91, 2008.

[52] A. R. Groves and J. C. Lawrence, "Aliginate dressing as a donor site haemostat," Annals of the Royal College of Surgeons of England, vol. 68, no. 1, pp. 27-28, 1986.

[53] H. C. Segal, B. J. Hunt, and K. Gilding, "The effects of alginate and non-alginate wound dressings on blood coagulation and platelet activation," Journal of Biomaterials Applications, vol. 12, no. 3, pp. 249-257, 1998.

[54] M. Otterlei, K. Ostgaard, G. Skjak-Braek, O. Smidsrod, P. SoonShiong, and T. Espevik, "Induction of cytokine production from human monocytes stimulated with alginate," Journal of Immunotherapy, vol. 10, no. 4, pp. 286-291, 1991.
[55] U. Zimmermann, G. Klock, K. Federlin et al., "Production of mitogen-contamination free alginates with variable ratios of mannuronic acid to guluronic acid by free flow electrophoresis," Electrophoresis, vol. 13, no. 5, pp. 269-274, 1992.

[56] Q. Sun, E. A. Silva, A. Wang et al., "Sustained release of multiple growth factors from injectable polymeric system as a novel therapeutic approach towards angiogenesis," Pharmaceutical Research, vol. 27, no. 2, pp. 264-271, 2010.

[57] A. Leung, L. K. Nielsen, M. Trau, and N. E. Timmins, “Tissue transplantation by stealth-coherent alginate microcapsules for immunoisolation," Biochemical Engineering Journal, vol. 48, no. 3, pp. 337-347, 2010.

[58] R. M. Hernández, G. Orive, A. Murua, and J. L. Pedraz, "Microcapsules and microcarriers for in situ cell delivery," Advanced Drug Delivery Reviews, vol. 62, no. 7-8, pp. 711-730, 2010.

[59] T. A. Becker, D. R. Kipke, and T. Brandon, "Calcium alginate gel: a biocompatible and mechanically stable polymer for endovascular embolization," Journal of Biomedical Materials Research A, vol. 54, no. 1, pp. 76-86, 2001.

[60] N. Butoescu, O. Jordan, and E. Doelker, "Intra-articular drug delivery systems for the treatment of rheumatic diseases: a review of the factors influencing their performance," European Journal of Pharmaceutics and Biopharmaceutics, vol. 73, no. 2, pp. 205-218, 2009.

[61] T. Igarashi, N. Iwasaki, D. Kawamura et al., "Therapeutic effects of intra-articular ultrapurified low endotoxin alginate administration on experimental osteoarthritis in rabbits," Cartilage, vol. 3, no. 1, pp. 70-78, 2012.

[62] S. Alipour, H. Montaseri, and M. Tafaghodi, "Preparation and characterization of biodegradable paclitaxel loaded alginate microparticles for pulmonary delivery," Colloids and Surfaces B: Biointerfaces, vol. 81, no. 2, pp. 521-529, 2010.

[63] W. J. Cho, S. H. Oh, and J. H. Lee, "Alginate film as a novel postsurgical tissue adhesion barrier," Journal of Biomaterials Science, Polymer Edition, vol. 21, no. 6-7, pp. 701-713, 2010.

[64] D. Pal and A. K. Nayak, "Novel tamarind seed polysaccharidealginate mucoadhesive microspheres for oral gliclazide delivery: in vitro-in vivo evaluation," Drug Delivery, vol. 19, no. 3, pp. 123-131, 2012.

[65] S. B. Patil, A. Kaul, A. Babbar, R. Mathur, A. Mishra, and K. K. Sawant, "In vivo evaluation of alginate microspheres of carvedilol for nasal delivery," Journal of Biomedical Materials Research B: Applied Biomaterials, vol. 100, no. 1, pp. 249-255, 2012.

[66] M. H. Aburahma and A. A. Mahmoud, "Biodegradable ocular inserts for sustained delivery of brimonidine tartarate: preparation and in vitro/in vivo evaluation," AAPS PharmSciTech, vol. 12, no. 4, pp. 1335-1347, 2011.

[67] D. H. Shastri, S. T. Prajapati, and L. D. Patel, "Design and development of thermoreversible ophthalmic in situ hydrogel of moxifloxacin HCL," Current Drug Delivery, vol. 7, no. 3, pp. 238-243, 2010.

[68] S. N. Pawar and K. J. Edgar, "Chemical modification of alginates in organic solvent systems," Biomacromolecules, vol. 12, no. 11, pp. 4095-4103, 2011.

[69] S. B. Shah, C. P. Patel, and H. C. Trivedi, "Ceric-induced grafting of acrylate monomers onto sodium alginate," Carbohydrate Polymers, vol. 26, no. 1, pp. 61-67, 1995.

[70] T. Tripathy and R. P. Singh, "Characterization of polyacrylamide-grafted sodium alginate: a novel polymeric flocculant," Journal of Applied Polymer Science, vol. 81, no. 13, pp. 3296$3308,2001$. 
[71] R. J. Coleman, G. Lawrie, L. K. Lambert, M. Whittaker, K. S. Jack, and L. Grøndahl, "Phosphorylation of alginate: synthesis, characterization, and evaluation of in vitro mineralization capacity," Biomacromolecules, vol. 12, no. 4, pp. 889-897, 2011.

[72] M.-C. Carré, C. Delestre, P. Hubert, and E. Dellacherie, "Covalent coupling of a short polyether on sodium alginate: synthesis and characterization of the resulting amphiphilic derivative," Carbohydrate Polymers, vol. 16, no. 4, pp. 367-379, 1991.

[73] J. Su and H. Tan, "Alginate-based biomaterials for regenerative medicine applications," Materials, vol. 6, no. 4, pp. 1285-1309, 2013.

[74] J. A. Rowley and D. J. Mooney, "Alginate type and RGD density control myoblast phenotype," Journal of Biomedical Materials Research, vol. 60, no. 2, pp. 217-223, 2002.

[75] G. Fundueanu, C. Nastruzzi, A. Carpov, J. Desbrieres, and M. Rinaudo, "Physico-chemical characterization of Ca-alginate microparticles produced with different methods," Biomaterials, vol. 20, no. 15, pp. 1427-1435, 1999.

[76] J.-H. Cui, J.-S. Goh, S.-Y. Park, P.-H. Kim, and B.-J. Lee, "Preparation and physical characterization of alginate microparticles using air atomization method," Drug Development and Industrial Pharmacy, vol. 27, no. 4, pp. 309-319, 2001.

[77] S. Cascone, G. Lamberti, G. Titomanlio, A. A. Barba, and M. D’Amore, "Microencapsulation effectiveness of small active molecules in biopolymer by ultrasonic atomization technique," Drug Development and Industrial Pharmacy, vol. 38, no. 12, pp. 1486-1493, 2012.

[78] C. P. Reis, R. J. Neufeld, S. Vilela, A. J. Ribeiro, and F. Veiga, "Review and current status of emulsion/dispersion technology using an internal gelation process for the design of alginate particles," Journal of Microencapsulation, vol. 23, no. 3, pp. 245257, 2006.

[79] K.-S. Huang, Y.-S. Lin, C.-H. Yang, C.-W. Tsai, and M.-Y. Hsu, "In situ synthesis of twin monodispersed alginate microparticles," Soft Matter, vol. 7, no. 14, pp. 6713-6718, 2011.

[80] M. Saravanan and K. P. Rao, "Pectin-gelatin and alginate-gelatin complex coacervation for controlled drug delivery: influence of anionic polysaccharides and drugs being encapsulated on physicochemical properties of microcapsules," Carbohydrate Polymers, vol. 80, no. 3, pp. 808-816, 2010.

[81] P. F. Builders, O. O. Kunle, L. C. Okpaku, M. I. Builders, A. A. Attama, and M. U. Adikwu, "Preparation and evaluation of mucinated sodium alginate microparticles for oral delivery of insulin," European Journal of Pharmaceutics and Biopharmaceutics, vol. 70, no. 3, pp. 777-783, 2008.

[82] M. S. Crcarevska, M. G. Dodov, and K. Goracinova, "Chitosan coated Ca-alginate microparticles loaded with budesonide for delivery to the inflamed colonic mucosa," European Journal of Pharmaceutics and Biopharmaceutics, vol. 68, no. 3, pp. 565-578, 2008.

[83] T. Suksamran, P. Opanasopit, T. Rojanarata, T. Ngawhirunpat, U. Ruktanonchai, and P. Supaphol, "Biodegradable alginate microparticles developed by electrohydrodynamic spraying techniques for oral delivery of protein," Journal of Microencapsulation, vol. 26, no. 7, pp. 563-570, 2009.

[84] D. M. Hariyadi, T. Bostrom, B. Bhandari, and A. G. A. Coombes, "A novel impinging aerosols method for production of propranolol hydrochloride-loaded alginate gel microspheres for oral delivery," Journal of Microencapsulation, vol. 29, no. 1, pp. 6371, 2012.

[85] D. M. Hariyadi, S. C.-Y. Lin, Y. Wang et al., "Diffusion loading and drug delivery characteristics of alginate gel microparticles produced by a novel impinging aerosols method," Journal of Drug Targeting, vol. 18, no. 10, pp. 831-841, 2010.

[86] S. Iwanaga, N. Saito, H. Sanae, and M. Nakamura, "Facile fabrication of uniform size-controlled microparticles and potentiality for tandem drug delivery system of micro/nanoparticles," Colloids and Surfaces B: Biointerfaces, vol. 109, pp. 301-306, 2013.

[87] K. S. Huang, C. H. Yang, Y. S. Lin et al., "Electrostatic droplets assisted synthesis of alginate microcapsules," Drug Delivery and Translational Research, vol. 1, pp. 289-298, 2011.

[88] H. D. C. Smyth, D. Guzman-Villanueva, D. Herrera-Ruiz, and I. M. El-Sherbiny, "A novel aerosol method for the production of hydrogel particles," Journal of Nanomaterials, vol. 2011, Article ID 507508, 10 pages, 2011.

[89] P. Matricardi, C. di Meo, T. Coviello, and F. Alhaique, "Recent advances and perspectives on coated alginate microspheres for modified drug delivery," Expert Opinion on Drug Delivery, vol. 5, no. 4, pp. 417-425, 2008.

[90] J. Zarate, L. Virdis, G. Orive, M. Igartua, R. M. Hernndez, and J. L. Pedraz, "Design and characterization of calcium alginate microparticles coated with polycations as protein delivery system," Journal of Microencapsulation, vol. 28, no. 7, pp. 614620, 2011.

[91] A. M. Urbanska, E. D. Karagiannis, G. Guajardo, R. S. Langer, and D. G. Anderson, "Therapeutic effect of orally administered microencapsulated oxaliplatin for colorectal cancer," Biomaterials, vol. 33, no. 18, pp. 4752-4761, 2012.

[92] G. Coppi, V. Iannuccelli, N. Sala, and M. Bondi, "Alginate microparticles for Polymyxin B Peyer's patches uptake: microparticles for antibiotic oral administration," Journal of Microencapsulation, vol. 21, no. 8, pp. 829-839, 2004.

[93] K. Mladenovska, O. Cruaud, P. Richomme et al., "5-ASA loaded chitosan-Ca-alginate microparticles: preparation and physicochemical characterization," International Journal of Pharmaceutics, vol. 345, no. 1-2, pp. 59-69, 2007.

[94] M. Tafaghodi, S. A. S. Tabasi, and M. R. Jaafari, "Formulation, characterization and release studies of alginate microspheres encapsulated with tetanus toxoid," Journal of Biomaterials Science, Polymer Edition, vol. 17, no. 8, pp. 909-924, 2006.

[95] S. Jaya, T. D. Durance, and R. Wang, "Effect of alginate-pectin composition on drug release characteristics of microcapsules," Journal of Microencapsulation, vol. 26, no. 2, pp. 143-153, 2009.

[96] Z. Fenyvesi, A. Auner, D. Schmalz et al., "Preparation of pHsensitive beads for NSAID using three-component gel systems," Journal of Pharmaceutical Sciences, vol. 98, no. 11, pp. 42854295, 2009.

[97] D. Shi, R. Greever, and Y. Chen, "Preparation and characterization of novel sinomenine microcapsules for oral controlled drug delivery," Drug Development and Industrial Pharmacy, vol. 36, no. 4, pp. 482-489, 2010.

[98] Z. Makai, J. Bajdik, I. Eros, and K. Pintye-Hódi, "Evaluation of the effects of lactose on the surface properties of alginate coated trandolapril particles prepared by a spray-drying method," Carbohydrate Polymers, vol. 74, no. 3, pp. 712-716, 2008.

[99] B. Čalija, N. Cekić, S. Savić, D. Krajišnik, R. Daniels, and J. Milić, "An investigation of formulation factors affecting feasibility of alginate-chitosan microparticles for oral delivery of naproxen," Archives of Pharmacal Research, vol. 34, no. 6, pp. 919-929, 2011.

[100] V. Iannuccelli, M. Montanari, D. Bertelli, F. Pellati, and G. Coppi, "Microparticulate polyelectrolyte complexes for gentamicin transport across intestinal epithelia," Drug Delivery, vol. 18 , no. 1, pp. 26-37, 2011. 
[101] G. Coppi and V. Iannuccelli, "Alginate/chitosan microparticles for tamoxifen delivery to the lymphatic system," International Journal of Pharmaceutics, vol. 367, no. 1-2, pp. 127-132, 2009.

[102] R. V. Kulkarni, S. Mutalik, B. S. Mangond, and U. Y. Nayak, "Novel interpenetrated polymer network microbeads of natural polysaccharides for modified release of water soluble drug: in-vitro and in-vivo evaluation," Journal of Pharmacy and Pharmacology, vol. 64, no. 4, pp. 530-540, 2012.

[103] L. Chen and M. Subirade, "Alginate-whey protein granular microspheres as oral delivery vehicles for bioactive compounds," Biomaterials, vol. 27, no. 26, pp. 4646-4654, 2006.

[104] L. Chen and M. Subirade, "Effect of preparation conditions on the nutrient release properties of alginate-whey protein granular microspheres," European Journal of Pharmaceutics and Biopharmaceutics, vol. 65, no. 3, pp. 354-362, 2007.

[105] A. R. Kulkarni, K. S. Soppimath, T. M. Aminabhavi, and W. E. Rudzinski, "In-vitro release kinetics of cefadroxil-loaded sodium alginate interpenetrating network beads," European Journal of Pharmaceutics and Biopharmaceutics, vol. 51, no. 2, pp. 127-133, 2001.

[106] V. R. Babu, M. Sairam, K. M. Hosamani, and T. M. Aminabhavi, "Preparation of sodium alginate-methylcellulose blend microspheres for controlled release of nifedipine," Carbohydrate Polymers, vol. 69, no. 2, pp. 241-250, 2007.

[107] A. R. Kulkarni, K. S. Soppimath, T. M. Aminabhavi, and A. M. Dave, "Polymeric sodium alginate interpenetrating network beads for the controlled release of chlorpyrifos," Journal of Applied Polymer Science, vol. 85, no. 5, pp. 911-918, 2002.

[108] S. C. Angadi, L. S. Manjeshwa, and T. M. Aminabhavi, "Novel composite blend microbeads of sodium alginate coated with chitosan for controlled release of amoxicillin," International Journal of Biological Macromolecules, vol. 51, no. 1-2, pp. 45-55, 2012.

[109] N. Mennini, S. Furlanetto, M. Cirri, and P. Mura, "Quality by design approach for developing chitosan-Ca-alginate microspheres for colon delivery of celecoxib-hydroxypropyl- $\beta$ cyclodextrin-PVP complex," European Journal of Pharmaceutics and Biopharmaceutics, vol. 80, no. 1, pp. 67-75, 2012.

[110] N. K. Thakral, A. R. Ray, D. Bar-Shalom, A. H. Eriksson, and D. K. Majumdar, "The quest for targeted delivery in colon cancer: mucoadhesive valdecoxib microspheres," International Journal of Nanomedicine, vol. 6, pp. 1057-1068, 2011.

[111] P. B. Kajjari, L. S. Manjeshwar, and T. M. Aminabhavi, "Novel $\mathrm{pH}$ - and temperature-responsive blend hydrogel microspheres of sodium alginate and PNIPAAm- $g$-GG for controlled release of isoniazid," AAPS PharmSciTech, vol. 13, no. 4, pp. 1147-1157, 2012.

[112] S. A. Agnihotri, R. V. Kulkarni, N. N. Mallikarjuna, P. V. Kulkarni, and T. M. Aminabhavi, "Electrically modulated transport of diclofenac salts through hydrogels of sodium alginate, carbopol, and their blend polymers," Journal of Applied Polymer Science, vol. 96, no. 2, pp. 301-311, 2005.

[113] A. M. Zhu, J. H. Chen, Q. L. Liu, and Y. L. Jiang, "Controlled release of berberine hydrochloride from alginate microspheres embedded within carboxymethyl chitosan hydrogels," Journal of Applied Polymer Science, vol. 120, no. 4, pp. 2374-2380, 2011.

[114] H. Liu, C. Wang, Q. Gao, X. Liu, and Z. Tong, "Fabrication of novel core-shell hybrid alginate hydrogel beads," International Journal of Pharmaceutics, vol. 351, no. 1-2, pp. 104-112, 2008.

[115] H. Liu, C. Wang, Q. Gao et al., "Facile fabrication of welldefined hydrogel beads with magnetic nanocomposite shells,"
International Journal of Pharmaceutics, vol. 376, no. 1-2, pp. 9298, 2009.

[116] C.-Y. Yu, B.-C. Yin, W. Zhang, S.-X. Cheng, X.-Z. Zhang, and R.$\mathrm{X}$. Zhuo, "Composite microparticle drug delivery systems based on chitosan, alginate and pectin with improved $\mathrm{pH}$-sensitive drug release property," Colloids and Surfaces B: Biointerfaces, vol. 68, no. 2, pp. 245-249, 2009.

[117] A.-Z. Chen, M.-Y. Chen, S.-B. Wang, X.-N. Huang, Y.-G. Liu, and Z.-X. Chen, "Poly(L-histidine)-chitosan/alginate complex microcapsule as a novel drug delivery agent," Journal of Applied Polymer Science, vol. 124, no. 5, pp. 3728-3736, 2012.

[118] V. Saez, J. Ramón, C. Peniche, and E. Hardy, "Microencapsulation of alpha interferons in biodegradable microspheres," Journal of Interferon \& Cytokine Research, vol. 32, no. 7, pp. 299311, 2012.

[119] C. P. Reis, A. J. Ribeiro, S. Houng, F. Veiga, and R. J. Neufeld, "Nanoparticulate delivery system for insulin: design, characterization and in vitro/in vivo bioactivity," European Journal of Pharmaceutical Sciences, vol. 30, no. 5, pp. 392-397, 2007.

[120] B. Sarmento, A. Ribeiro, F. Veiga, D. Ferreira, and R. Neufeld, "Oral bioavailability of insulin contained in polysaccharide nanoparticles," Biomacromolecules, vol. 8, no. 10, pp. 3054-3060, 2007.

[121] B. Sarmento, A. Ribeiro, F. Veiga, P. Sampaio, R. Neufeld, and D. Ferreira, "Alginate/chitosan nanoparticles are effective for oral insulin delivery," Pharmaceutical Research, vol. 24, no. 12, pp. 2198-2206, 2007.

[122] C. B. Woitiski, R. J. Neufeld, A. J. Ribeiro, and F. Veiga, "Colloidal carrier integrating biomaterials for oral insulin delivery: influence of component formulation on physicochemical and biological parameters," Acta Biomaterialia, vol. 5, no. 7, pp. 2475-2484, 2009.

[123] S. Martins, B. Sarmento, E. B. Souto, and D. C. Ferreira, "Insulin-loaded alginate microspheres for oral delivery-effect of polysaccharide reinforcement on physicochemical properties and release profile," Carbohydrate Polymers, vol. 69, no. 4, pp. 725-731, 2007.

[124] Y. Zhang, W. Wei, P. Lv, L. Wang, and G. Ma, "Preparation and evaluation of alginate-chitosan microspheres for oral delivery of insulin," European Journal of Pharmaceutics and Biopharmaceutics, vol. 77, no. 1, pp. 11-19, 2011.

[125] D. M. Nathan, "Long-term complications of diabetes mellitus," The New England Journal of Medicine, vol. 328, no. 23, pp. 16761685, 1993.

[126] A. Schoubben, P. Blasi, S. Giovagnoli, L. Perioli, C. Rossi, and M. Ricci, "Novel composite microparticles for protein stabilization and delivery," European Journal of Pharmaceutical Sciences, vol. 36, no. 2-3, pp. 226-234, 2009.

[127] M. G. Sankalia, R. C. Mashru, J. M. Sankalia, and V. B. Sutariya, "Papain entrapment in alginate beads for stability improvement and site-specific delivery: physicochemical characterization and factorial optimization using neural network modeling," AAPS PharmSciTech, vol. 6, no. 2, article 31, pp. E209-E222, 2005.

[128] C. K. Simi and T. E. Abraham, "Encapsulation of crosslinked subtilisin microcrystals in hydrogel beads for controlled release applications," European Journal of Pharmaceutical Sciences, vol. 32, no. 1, pp. 17-23, 2007.

[129] H. Park, P.-H. Kim, T. Hwang et al., "Fabrication of cross-linked alginate beads using electrospraying for adenovirus delivery," International Journal of Pharmaceutics, vol. 427, no. 2, pp. 417425, 2012. 
[130] N. Nograles, S. Abdullah, M. N. Shamsudin, N. Billa, and R. Rosli, "Formation and characterization of pDNA-loaded alginate microspheres for oral administration in mice," Journal of Bioscience and Bioengineering, vol. 113, no. 2, pp. 133-140, 2012.

[131] C. Alvarez-Lorenzo, B. Blanco-Fernandez, A. M. Puga, and A. Concheiro, "Crosslinked ionic polysaccharides for stimulisensitive drug delivery," Advanced Drug Delivery Reviews, vol. 65, no. 9, pp. 1148-1171, 2013.

[132] X. Y. Li, X. Y. Kong, S. Shi et al., "Preparation of alginate coated chitosan microparticles for vaccine delivery," $B M C$ Biotechnology, vol. 8, article 89, 2008.

[133] R. Rastogi, Y. Sultana, M. Aqil et al., "Alginate microspheres of isoniazid for oral sustained drug delivery," International Journal of Pharmaceutics, vol. 334, no. 1-2, pp. 71-77, 2007.

[134] S. K. Prajapati, P. Tripathi, U. Ubaidulla, and V. Anand, "Design and development of gliclazide mucoadhesive microcapsules: in vitro and In vivo evaluation," AAPS PharmSciTech, vol. 9, no. 1, pp. 224-230, 2008.

[135] P. Sriamornsak and R. A. Kennedy, "Effect of drug solubility on release behavior of calcium polysaccharide gel-coated pellets," European Journal of Pharmaceutical Sciences, vol. 32, no. 3, pp. 231-239, 2007.

[136] M. Das and P. Senapati, "Furosemide-loaded alginate microspheres prepared by ionic cross-linking technique: morphology and release characteristics," Indian Journal of Pharmaceutical Sciences, vol. 70, no. 1, pp. 77-84, 2008.

[137] I. M. El-Sherbiny, M. Abdel-Mogib, A.-A. M. Dawidar, A. Elsayed, and H. D. C. Smyth, "Biodegradable pH-responsive alginate-poly (lactic-co-glycolic acid) nano/micro hydrogel matrices for oral delivery of silymarin," Carbohydrate Polymers, vol. 83, no. 3, pp. 1345-1354, 2011.

[138] S. Wittaya-Areekul, J. Kruenate, and C. Prahsarn, "Preparation and in vitro evaluation of mucoadhesive properties of alginate/chitosan microparticles containing prednisolone," International Journal of Pharmaceutics, vol. 312, no. 1-2, pp. 113118, 2006.

[139] S. K. Basu and A. Rajendran, "Studies in the development of nateglinide loaded calcium alginate and chitosan coated calcium alginate beads," Chemical \& Pharmaceutical Bulletin, vol. 56, no. 8, pp. 1077-1084, 2008.

[140] A. Abdelbary, N. A. El-Gendy, and A. Hosny, "Microencapsulation approach for orally extended delivery of glipizide: in vitro and in vivo evaluation," Indian Journal of Pharmaceutical Sciences, vol. 74, no. 4, pp. 319-330, 2012.

[141] B. Albertini, B. Vitali, N. Passerini et al., "Development of microparticulate systems for intestinal delivery of Lactobacillus acidophilus and Bifidobacterium lactis," European Journal of Pharmaceutical Sciences, vol. 40, no. 4, pp. 359-366, 2010.

[142] F. Shen, C. Poncet-Legrand, S. Somers et al., "Properties of a novel magnetized alginate for magnetic resonance imaging," Biotechnology and Bioengineering, vol. 83, no. 3, pp. 282-292, 2003.

[143] S. W. Zeilhuis, J. H. Seppenwoolde, C. J. G. Bakker et al., "Characterization of holmium loaded alginate microspheres for multimodality imaging and therapeutic applications," Journal of Biomedical Materials Research A, vol. 82, no. 4, pp. 892-898, 2007.

[144] J. Liu, Y. Zhang, C. Yan, C. Wang, R. Xu, and N. Gu, "Synthesis of magnetic/luminescent alginate-templated composite microparticles with temperature-dependent photoluminescence under high-frequency magnetic field," Langmuir, vol. 26, no. 24, pp. 19066-19072, 2010.

[145] L. S. Wang, M. C. Chuang, and J. A. Ho, "Nanotheranosticsa review of recent publications," International Journal of Nanomedicine, vol. 7, pp. 4679-4695, 2012.

[146] O. Borges, A. Cordeiro-da-Silva, S. G. Romeijn et al., "Uptake studies in rat Peyer's patches, cytotoxicity and release studies of alginate coated chitosan nanoparticles for mucosal vaccination," Journal of Controlled Release, vol. 114, no. 3, pp. 348-358, 2006.

[147] Y.-M. Yi, T.-Y. Yang, and W.-M. Pan, "Preparation and distribution of 5-fluorouracil $125 \mathrm{I}$ sodium alginate-bovine serum albumin nanoparticles," World Journal of Gastroenterology, vol. 5, no. 1, pp. 57-60, 1999.

[148] M. Rajaonarivony, C. Vauthier, G. Couarraze, F. Puisieux, and P. Couvreur, "Development of a new drug carrier made from alginate," Journal of Pharmaceutical Sciences, vol. 82, no. 9, pp. 912-917, 1993.

[149] Z. Ahmad, R. Pandey, S. Sharma, and G. K. Khuller, "Pharmacokinetic and pharmacodynamic behaviour of antitubercular drugs encapsulated in alginate nanoparticles at two doses," International Journal of Antimicrobial Agents, vol. 27, no. 5, pp. 420-427, 2006.

[150] J.-O. You and C.-A. Peng, "Calcium-alginate nanoparticles formed by reverse microemulsion as gene carriers," Macromolecular Symposia, vol. 219, pp. 147-153, 2004.

[151] A. H. E. MacHado, D. Lundberg, A. J. Ribeiro et al., "Preparation of calcium alginate nanoparticles using water-in-oil (W/O) nanoemulsions," Langmuir, vol. 28, no. 9, pp. 4131-4141, 2012.

[152] B. Sarmento, S. Martins, A. Ribeiro, F. Veiga, R. Neufeld, and D. Ferreira, "Development and comparison of different nanoparticulate polyelectrolyte complexes as insulin carriers," International Journal of Peptide Research and Therapeutics, vol. 12, no. 2, pp. 131-138, 2006.

[153] B. Sarmento, A. J. Ribeiro, F. Veiga, D. C. Ferreira, and R. J. Neufeld, "Insulin-loaded nanoparticles are prepared by alginate lonotropic pre-gelation followed by chitosan polyelectrolyte complexation," Journal of Nanoscience and Nanotechnology, vol. 7, no. 8, pp. 2833-2841, 2007.

[154] Z. S. Haidar, R. C. Hamdy, and M. Tabrizian, "Protein release kinetics for core-shell hybrid nanoparticles based on the layerby-layer assembly of alginate and chitosan on liposomes," Biomaterials, vol. 29, no. 9, pp. 1207-1215, 2008.

[155] O. Borges, M. Silva, A. de Sousa, G. Borchard, H. E. Junginger, and A. Cordeiro-da-Silva, "Alginate coated chitosan nanoparticles are an effective subcutaneous adjuvant for hepatitis B surface antigen," International Immunopharmacology, vol. 8, no. 13-14, pp. 1773-1780, 2008.

[156] J. S. Hong, W. N. Vreeland, S. H. D. Lacerda, L. E. Locascio, M. Gaitan, and S. R. Raghavan, "Liposome-templated supramolecular assembly of responsive alginate nanogels," Langmuir, vol. 24, no. 8, pp. 4092-4096, 2008.

[157] Y. Chen, X. Lin, H. Park, and R. Greever, "Study of artemisinin nanocapsules as anticancer drug delivery systems," Nanomedicine: Nanotechnology, Biology, and Medicine, vol. 5, no. 3, pp. 316-322, 2009.

[158] C. B. Woitiski, B. Sarmento, R. A. Carvalho, R. J. Neufeld, and F. Veiga, "Facilitated nanoscale delivery of insulin across intestinal membrane models," International Journal of Pharmaceutics, vol. 412, no. 1-2, pp. 123-131, 2011.

[159] W. Paul and C. P. Sharma, "Synthesis and characterization of alginate coated zinc calcium phosphate nanoparticles for 
intestinal delivery of insulin," Process Biochemistry, vol. 47, no. 5, pp. 882-886, 2012.

[160] N. Zhang, J. Li, W. Jiang et al., "Effective protection and controlled release of insulin by cationic $\beta$-cyclodextrin polymers from alginate/chitosan nanoparticles," International Journal of Pharmaceutics, vol. 393, no. 1-2, pp. 212-218, 2010.

[161] S. Ghaffari, J. Varshosaz, I. Haririan, M. R. Khoshayand, S. Azarmi, and T. Gazori, "Ciprofloxacin loaded alginate/chitosan and solid lipid nanoparticles, preparation, and characterization," Journal of Dispersion Science and Technology, vol. 33, no. 5, pp. 685-689, 2012.

[162] G. Mahidhara, R. K. Kanwar, and J. R. Kanwar, "Novel nanoplatform for oral delivery of anti-cancer biomacromolecules," Journal of Nanotechnology, vol. 9, no. 10-12, pp. 942-960, 2012.

[163] B. Malik, A. K. Goyal, T. S. Markandeywar, G. Rath, F. Zakir, and S. P. Vyas, "Microfold-cell targeted surface engineered polymeric nanoparticles for oral immunization," Journal of Drug Targeting, vol. 20, no. 1, pp. 76-84, 2012.

[164] R. Pandey, Z. Ahmad, S. Sharma, and G. K. Khuller, "Nanoencapsulation of azole antifungals: potential applications to improve oral drug delivery," International Journal of Pharmaceutics, vol. 301, no. 1-2, pp. 268-276, 2005.

[165] Z. Ahmad, S. Sharma, and G. K. Khuller, "Chemotherapeutic evaluation of alginate nanoparticle-encapsulated azole antifungal and antitubercular drugs against murine tuberculosis," Nanomedicine: Nanotechnology, Biology, and Medicine, vol. 3, no. 3, pp. 239-243, 2007.

[166] S. Arora, S. Gupta, R. K. Narang, and R. D. Budhiraja, "Amoxicillin loaded chitosan-alginate polyelectrolyte complex nanoparticles as mucopenetrating delivery system for H. pylori," Scientia Pharmaceutica, vol. 79, no. 3, pp. 673-694, 2011.

[167] F. Chen, Z.-R. Zhang, F. Yuan, X. Qin, M. Wang, and Y. Huang, "In vitro and in vivo study of $\mathrm{N}$-trimethyl chitosan nanoparticles for oral protein delivery," International Journal of Pharmaceutics, vol. 349, no. 1-2, pp. 226-233, 2008.

[168] S.-J. Yang, F.-H. Lin, H.-M. Tsai et al., "Alginate-folic acidmodified chitosan nanoparticles for photodynamic detection of intestinal neoplasms," Biomaterials, vol. 32, no. 8, pp. 2174-2182, 2011.

[169] C. R. Oliveira, C. M. F. Rezende, M. R. Silva, A. P. Pego, O. Borges, and A. M. Goes, "A new strategy based on Smrho protein loaded chitosan nanoparticles as a candidate oral vaccine against schistosomiasis," PLOS Neglected Tropical Diseases, vol. 6, no. 11, article 1894, 2012.

[170] W. He, Z. Guo, Y. Wen et al., "Alginate-graft-PEI as a gene delivery vector with high efficiency and low cytotoxicity," Journal of Biomaterials Science, Polymer Edition, vol. 23, no. 1-4, pp. 315-331, 2012. 

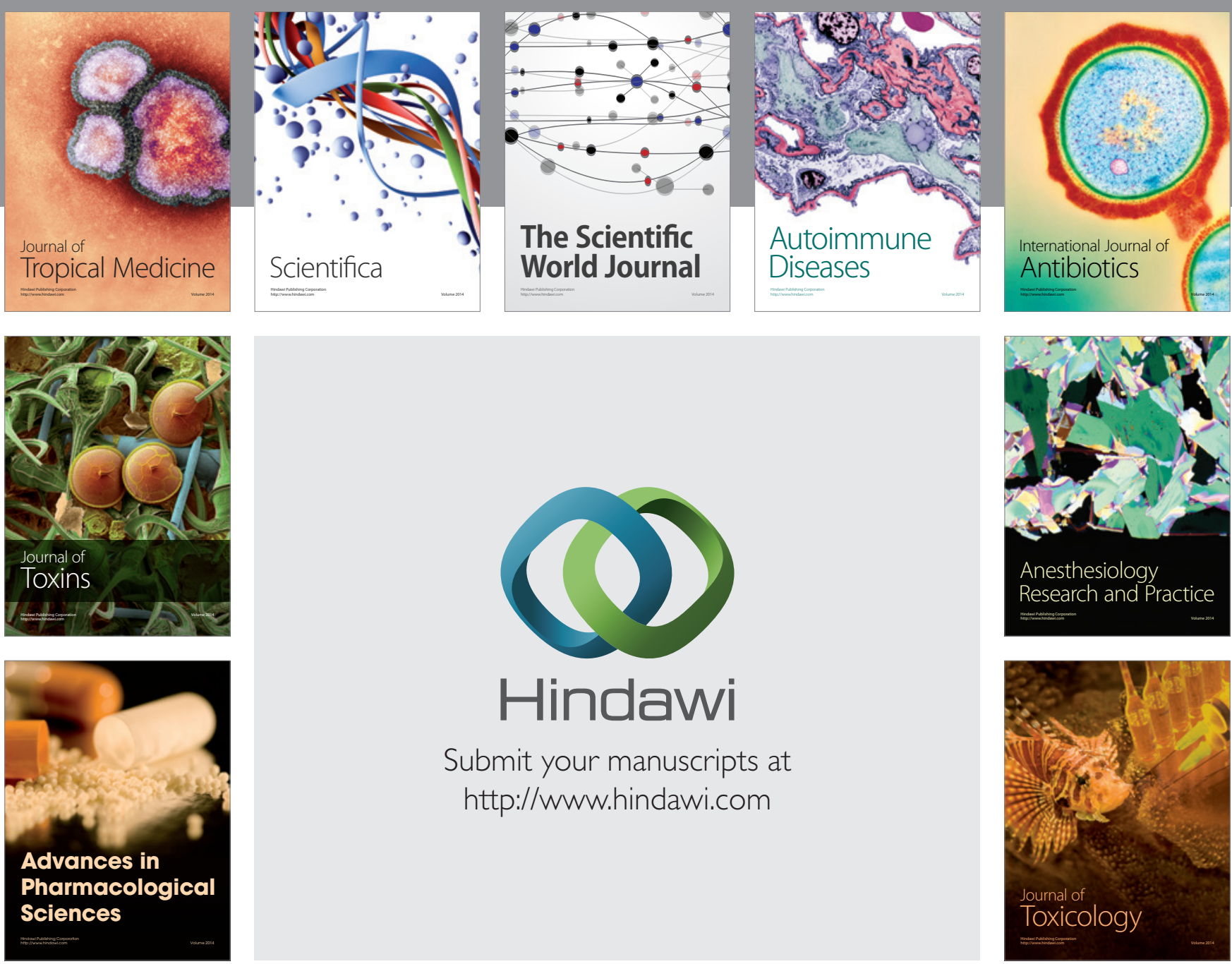

\section{Hindawi}

Submit your manuscripts at

http://www.hindawi.com
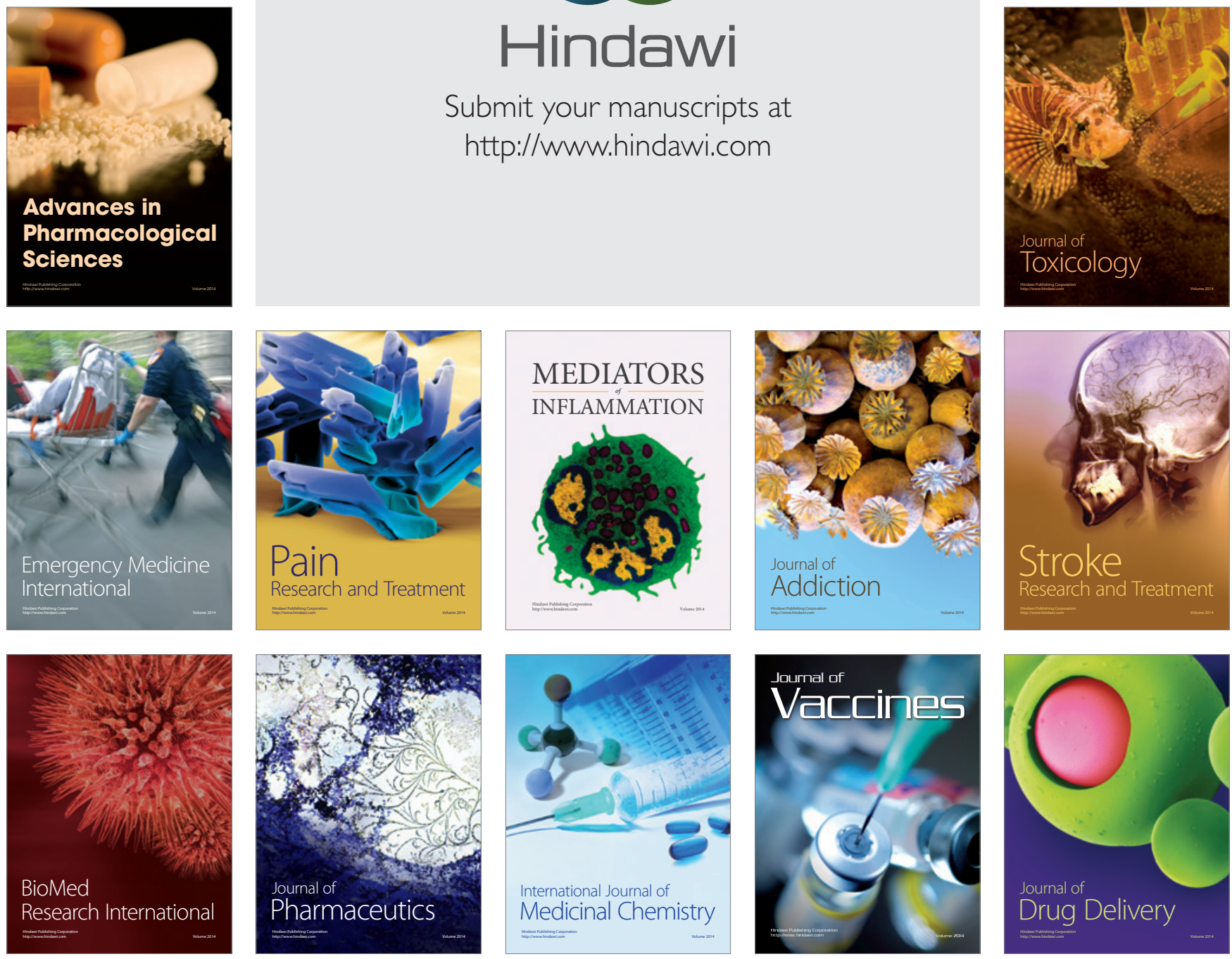